Volume 7(2), 45-71. http://dx.doi.org/10.18608/jla.2020.72.3

\title{
Analytics of Learning Strategies: Role of Course Design and Delivery Modality
}

\author{
Wannisa Matcha ${ }^{1}$, Dragan Gašević ${ }^{2}$, Nora'ayu Ahmad Uzir ${ }^{3}$, Jelena Jovanović ${ }^{4}$, \\ Abelardo Pardo ${ }^{5}$, Lisa Lim ${ }^{6}$, Jorge Maldonado-Mahauad ${ }^{7}$, Sheridan Gentili ${ }^{8}$, \\ Mar Pérez-Sanagustín ${ }^{9}$, Yi-Shan Tsai ${ }^{10}$
}

\begin{abstract}
Generalizability of the value of methods based on learning analytics remains one of the big challenges in the field of learning analytics. One approach to testing generalizability of a method is to apply it consistently in different learning contexts. This study extends a previously published work by examining the generalizability of a learning analytics method proposed for detecting learning tactics and strategies from trace data. The method was applied to the datasets collected in three different course designs and delivery modalities, including flipped classroom, blended learning, and massive open online course. The proposed method combines process mining and sequence analysis. The detected learning strategies are explored in terms of their association with academic performance. The results indicate the applicability of the proposed method across different learning contexts. Moreover, the findings contribute to the understanding of the learning tactics and strategies identified in the trace data: learning tactics proved to be responsive to the course design, whereas learning strategies were found to be more sensitive to the delivery modalities than to the course design. These findings, well aligned with self-regulated learning theory, highlight the association of learning contexts with the choice of learning tactics and strategies.
\end{abstract}

\section{Notes for Practice}

- Explorations of the detected learning tactics and strategies need to consider both sequential and temporal characteristics.

- Learning tactics and strategies are context dependent; therefore, specific learning tactics and strategies have to be interpreted in the particular learning context from which the data originate.

- Detected learning tactics should reflect the instructional course design.

\section{Keywords}

Learning strategies, learning tactics, data mining, self-regulated learning, modality, course design

Submitted: 07.01.2020 — Accepted: 28.07.2020 — Published: 19.09.2020

Corresponding author ${ }^{1}$ Email: w.matcha@ed.ac.uk Address: School of Informatics, University of Edinburgh, 10 Crichton Street, Edinburgh, EH8 9AB, Scotland, UK, and Faculty of Communication Sciences, Prince of Songkla University, Pattani Campus A. Muang Pattani 94000, Pattani, Thailand

2Email: dragan.gasevic@monash.edu Address: Faculty of Information Technology, Monash University, Melbourne, VIC 3800, Australia, and University of Edinburgh, 10 Crichton Street, Edinburgh, EH8 9AB, Scotland, UK

${ }^{3}$ Email: nora'ayu590@uitm.edu.my Address: School of Informatics, University of Edinburgh, 10 Crichton Street, Edinburgh, EH8 9AB, Scotland, UK, and Universiti Teknologi MARA, Seksyen U10, 40150, Shah Alam, Selangor, Malaysia

${ }^{4}$ Email: jelena.jovanovic@fon.bg.ac.rs Address: Faculty of Organizational Sciences, University of Belgrade, Jove llica 154, 11000, Belgrade, Serbia

${ }^{5}$ Email: abelardo.pardo@unisa.edu.au Address: University of South Australia, Adelaide, SA 5000, Australia

${ }^{6}$ Email: lisa.lim@unisa.edu.au Address: University of South Australia, Adelaide, SA 5000, Australia

${ }^{7}$ Email: jorge.maldonado@ucuenca.edu.ec Address: Pontificia Universidad Católica de Chile, Av. Vicuña Mackenna 4860, Región Metropolitana, Santiago, Chile, and Universidad de Cuenca, Avda. Libertador Bernardo O'Higgins 390, Cuenca, Ecuador

${ }^{8}$ Email: sheridan.gentil@unisa.edu.au Address: Teaching Innovation Unit, University of South Australia, City West Campus, Adelaide, SA 5000, Australia

${ }^{9}$ Email: mar.perez-sanagustin@irit.fr Address: Pontificia Universidad Católica de Chile, Av. Vicuña Mackenna 4860, Región Metropolitana, Santiago, Chile, and Université Paul Sabatier Toulouse III, Institute de Recherche en Informatique de Toulouse (IRIT), 118, route de Narbonne, 31062, Toulouse, France

${ }^{10}$ Email: yi-shan.tsai@ed.ac.uk Address: School of Informatics, University of Edinburgh, 10 Crichton Street, Edinburgh, EH8 9AB, Scotland, UK ISSN 1929-7750 (online). The Journal of Learning Analytics works under a Creative Commons License, Attribution - NonCommercial -NoDerivs 3.0 Unported (CC BY-NC-ND 3.0) 


\section{Introduction}

Self-regulated learning (SRL) skills are essential for successful learning in technology-enhanced learning environments. Among the key SRL skills are those related to the ability to identify effective learning strategies and knowing when and how to apply them (Winne \& Hadwin, 1998; Lust, Elen, \& Clarebout, 2013a). Winne and Hadwin (1998) assert that the choice of learning strategy is influenced by cognitive and task conditions; that is, students take into account the learning context when selecting a learning strategy.

The structure of the learning context is shaped by multiple factors that may facilitate or inhibit the construction of knowledge (Tessmer \& Richey, 1997). In a technology-enhanced learning environment, two main factors that shape learning context are instructional design and learning modality. Instructional design or course design refers to the structure of the learning topics and the corresponding learning tasks designed to guide learning. Instructional design is typically driven by the nature of the discipline and the pedagogical approaches chosen to scaffold learning. For example, computer programming courses tend to rely on problem-solving and practical exercises, whereas humanities courses may require more theoretical development and discussion. The design of a course is also influenced by the delivery modalities, which refer to how and when learning activities are facilitated. For example, in a massive open online course (MOOC) setting, learning activities take place online and offer flexibility in terms of free enrolment as well as when and where learners engage with the learning activities. Blended learning (BL) relies on online learning activities as a complement to support face-to-face learning activities, such that the online component is used during the pre-course preparations, with in-class activities, and/or as part of revision. Closely related to the BL modality is the flipped classroom (FC), where the emphasis is on promoting active learning (Pardo, Gašević, Jovanović, Dawson, \& Mirriahi, 2018). In this mode, two components of learning settings are typically involved: (i) online preparatory activities that are offered to students to prepare for (ii) face-to-face learning sessions.

The variation in course structures, learning tasks, and delivery modalities contributes to how learners adapt and adopt learning tactics and strategies as part of their studies (see Section 2.1 for definitions). Still, the role of learning context in the selection and adaptation of learning tactics and strategies remains largely unexplored - only a few studies have explored learning tactics and strategies adopted by students across different learning contexts (Broadbent, 2017). One possible reason is the difficulty in accurately detecting learning tactics and strategies used by students (Matcha, Ahmad Uzir, Gašević, \& Pardo, 2019). To overcome this limitation in the literature, research in learning analytics has focused on the development of data analytic methods to mine trace data to detect learning patterns indicative of learning tactics and strategies. Nonetheless, the methods currently reported in the learning analytics literature are usually context specific and raise the question of their applicability across different learning contexts.

In this study, we replicate the previous study done by Matcha, Gašević, Ahmad Uzir, Jovanović, and Pardo (2019) and validate an analytics method to detect learning tactics and strategies used by students when they interact with online learning activities in different learning contexts. The previous study demonstrated the use of this analytic method in detecting learning strategies in trace data about students' online activities performed during their preparation for the face-to-face component of an FC course (Matcha, Gašević, Ahmad Uzir, Jovanović, \& Pardo, 2019). That work opened up a question regarding the applicability of the proposed method in different learning contexts. This paper, therefore, extends our original study to explore that question. The examined learning contexts are based on three different delivery modalities (BL, FC, and MOOC) and two different course designs (problem-solving and practice-based designs). We also examined how academic performance was associated with students' choice of learning strategies.

\section{Literature Review}

\subsection{Learning Strategies and Learning Modalities}

The terms learning strategy and learning tactic are often used interchangeably in the literature, although they refer to quite different concepts (Derry, 1989; Malmberg, Järvelä, \& Kirschner, 2014). A learning tactic is a learning technique or a cognitive operation used by a student to perform a particular task (Derry, 1989; Malmberg, Järvenoja, \& Järvelä, 2010). Students often combine two or more tactics to accomplish their learning objectives (Derry, 1989; Rachal, Daigle, \& Rachal, 2007). Learning strategies, on the other hand, can be defined as "a coordinated set of study tactics that are directed by learning goal, and that are aimed at acquiring a new skill or gaining understanding" (Malmberg et al., 2014, p. 116). Learning strategies, therefore, change and develop according to a learning situation and involve selecting, combining, coordinating, and utilizing cognitive operations and techniques (i.e., learning tactics), directed by the learning goal (Winne \& Hadwin, 1998).

Based on the model of SRL proposed by Winne and Hadwin (1998), the selection of learning tactics or strategies is driven by internal (e.g., cognitive) and external (e.g., task-related) conditions. In particular, acting as agents, learners select tactics and strategies based on several factors, including their knowledge of the task at hand, tactics, and strategies; the available learning materials; instructional cues; and their motivation, beliefs, and goals (Winne, 2013). By examining the products of 
their learning and where they stand with respect to the expectations or learning goals, students can reflect on their performance and the effectiveness of their tactics and strategies. As a consequence, their internal conditions are updated, and their selection of strategies and tactics can be changed (Winne \& Hadwin, 1998).

It has long been clearly noted by many scholars (e.g., Winne and Hadwin (1998); Zimmerman (1986)) that learning tactics and strategies are influenced by external conditions. These conditions are shaped by how the courses were designed and delivered. For instance, technology has been diversely applied in current education to support learning. This has resulted in different learning modalities, BL and fully online learning being among the most prominent forms.

BL refers to a learning approach that combines face-to-face classroom with technology-supported online learning activities (Bernard, Borokhovski, Schmid, Tamim, \& Abrami, 2014). Technology is used to support various aspects of learning within this setting, such as preparation, in-class participation, and revision. The online section of BL is generally provided through digital learning tools that require students to self-direct their learning (Bernard et al., 2014; Zhu, Au, \& Yates, 2016). It is important to recognize that online learning materials in this setting are not a replacement for face-to-face learning activities - they serve as complementary activities to support face-to-face learning.

Closely related to BL is FC. Its key distinctive feature is that learning activities for teaching students the basic concepts and facts are carried out online, before the face-to-face sessions, whereas the face-to-face time is devoted to further knowledge construction through active learning (Pardo et al., 2018). Students are responsible for regulating their learning to construct the knowledge required before attending face-to-face sessions (O'Flaherty \& Phillips, 2015). The face-to-face sessions seek to promote the development of deep understanding, the rectification of misunderstanding and confusion (Rahman et al., 2015), and the development of problem-solving and critical-thinking skills (Freeman et al., 2014; O'Flaherty \& Phillips, 2015; Pardo, 2018).

MOOCs rose to prominence in 2012 by offering fully online learning at practically no cost to students. MOOC-based learning relies heavily on students' ability to regulate their learning and manage their time (Kizilcec, Pérez-Sanagustín, \& Maldonado, 2017; Eriksson, Adawi, \& Stöhr, 2017). Several researchers and practitioners have adopted MOOCs as a way of transforming traditional classroom-based courses into BL mode (Rodríguez, Correa, Pérez-Sanagustín, Pertuze, \& Alario-Hoyos, 2017; Pérez-Sanagustín, Hilliger, Alario-Hoyos, Kloos, \& Rayyan, 2017).

Self-regulated learning skills and application of effective learning strategies are essential for different learning modalities. For instance, Zhu et al. (2016) found that in a BL context, self-regulation strategies were predictive of academic performance. Furthermore, research has found that the ineffective use of learning resources and poor study tactics had a negative impact on learning performance (Lust, Elen, \& Clarebout, 2013b). Similarly, Lai and Hwang (2016) found that in an FC-based course, students with high SRL scores performed significantly better than those who reported having low SRL scores. In the MOOC context, research found that high-performing students employed different learning strategies than lower-performance students (Nugent, Guru, \& Namuth-Covert, 2018). Eriksson et al. (2017) relied on students' self-reports to examine the factors that contributed to the completion of a MOOC and identified motivation, time management, and learning strategies as the prominent factors reported by learners.

Research published thus far clearly highlights the importance of employing effective learning strategies across different learning modalities. However, research has also reported that students' skills in regulating and modifying their learning strategies to meet the course requirements are often underdeveloped (Fincham, Gašević, Jovanović, \& Pardo, 2018; Lust et al., 2013a). Guiding students to select effective learning strategies is, therefore, important (Rachal et al., 2007). However, because of the difficulty in obtaining timely and informative insight into students' learning tactics and strategies, it has not been possible to provide the required support and guidance for learning strategy selection and regulation (Matcha, Ahmad Uzir, et al., 2019).

\subsection{Detection of Learning Tactics and Strategies}

Traditionally, learning tactics and strategies have been detected using self-reporting instruments such as surveys and think-aloud protocols. However, learners are not always accurate in reporting how they learn (Winne, 2013). For instance, think-aloud protocols can introduce cognitive overload because students are required to elaborate and justify their actions out loud while learning (Winne, 2013). By comparing actual learning activities to the self-reports, Hadwin, Nesbit, Jamieson-Noel, Code, and Winne (2007) found that self-reports did not reflect students' actual behaviour. Moreover, self-reports usually fail to capture how strategies develop over time. The use of learning trace data allows for an understanding of students' actual learning behaviour without intervening in their learning or inadvertently increasing their cognitive load. Zhou and Winne (2012) assert that trace data were better correlated to students' learning achievement than self-reports. Still, self-reports are successful in capturing students' perceptions and intentions and could assist in understanding how students choose to act. Thus, Zhou and Winne (2012) refer to the insights obtained through self-reports as "perceived intentions." On the other hand, data about students' actual learning behaviours, as recorded in the database of the learning platform, reflect students' "realized intentions."

The use of trace data allows the temporal dimension of learning tactics and strategies to be examined (Winne, 2017). In particular, learning tactics and strategies can be considered sequences of events, with each event being centred on one learning 
action (Hadwin et al., 2007; Molenaar, 2014). Such representation recognizes tactics and strategies as being dynamic, based on shifts from one action to another, and developing over time (Winne, Jamieson-Noel, \& Muis, 2002). As already highlighted, a learning tactic is considered an operation performed by a student to complete a learning task. This operation is composed of a sequence of actions and, hence, is recognized as a tactic (Derry, 1989). Scrutinizing learning tactics at the session level (i.e., within a particular period of time during which students were continuously interacting with learning materials) can provide a close observation of how students engaged in the learning process (Fincham et al., 2018). A learning strategy is defined as the application of one or more learning tactics (Malmberg et al., 2014), and, therefore, it can be identified by detecting patterns in students' learning paths, that is, the regulation of sequences of learning tactics. To sum up, understanding the temporal and sequential dimensions of learning events could shed some light on how tactics and strategies have developed and changed and allow for the detection of situations where transitions between states happen (Molenaar, 2014). Such patterns of events evolve over time and become a characteristic of one's learning. This characteristic may be considered as an aptitude that could predict one's future behaviour (Winne et al., 2002).

The detection of learning strategies using trace data has been the focus of several research studies. At the core of these studies is the use of process- and sequence-mining techniques to analyze trace data. For example, Maldonado-Mahauad, Pérez-Sanagustín, Kizilcec, Morales, and Munoz-Gama (2018) classify learning patterns, detected at the session level by using a process-mining technique, into seven types: (1) only video lecture — sessions in which students mainly interacted with the video contents; (2) only assessment - learning sessions in which students only accessed the assessment activities; (3) explore - sessions in which students were superficially accessing the assessment activities and video contents; (4) assessment try to video lecture - sessions in which students began to learn by accessing the assessment items and then switched to video content; (5) video lecture complete to assessment try - sessions in which students completed a video lecture but only accessed assessment activities; (6) video lecture to assessment pass - sessions where students watched a video lecture, followed by passing an assessment; and (7) other. These types of learning patterns were triangulated with students' self-reported data about self-regulation strategies. This resulted in the identification of three strategy groups of learners based on the data collected from three MOOCs. Specifically, Maldonado-Mahauad and colleagues found that comprehensive learners followed the course structure step by step, while targeting learners focused on specific learning activities to help them pass the course. Both of these groups showed higher academic performance than the sampling learners, who showed low and inconsistent engagement. The combined use of sequence mining and unsupervised machine learning is another common approach to detecting learning strategies from trace data. For example, Jovanović, Gašević, Dawson, Pardo, and Mirriahi (2017) used a sequence-mining technique together with agglomerative hierarchical clustering to detect learning strategies based on students' sequences of actions recorded when preparing online for an FC course. They identified four groups of learning tactics based on the patterns of learning actions within learning sessions, including sessions highly focused on (1) reading materials, (2) summative assessment, (3) formative assessment, and (4) video watching followed by assessment activities. Based on the regularity of the identified session-level learning patterns, they detected five groups of learners, including the intensive - highly active group, who applied a variety of learning tactics; the strategic - highly active group, with emphasis on interaction with summative and formative assessments; the highly strategic group, who focused on summative assessment and reading materials; the selective group, who focused on summative assessments with a low engagement with reading materials; and the highly selective group, who only applied the summative assessment-related tactic. Using the same course as the context of their study, Fincham et al. (2018) extracted learning tactics from trace data across three consecutive course offerings by using hidden Markov models (HMMs) and identified learning strategies by examining sequences of the detected tactics separately in the first and second half of the semester. The detected tactics and strategies were explained based on the distribution of learning actions. Given the same data, Matcha, Gašević, Ahmad Uzir, Jovanović, and Pardo (2019) combined first-order Markov models (FOMMs) and the expectation-maximization (EM) algorithm to detect learning tactics across the three course offerings of the same course as Fincham et al. (2018). Despite the methodological differences, the results of the two studies were consistent. That is, students who employed multiple learning tactics and were highly engaged in learning activities (i.e., those who adopted the deep approach to learning) tended to perform better. Those who applied a surface learning strategy with a low level of engagement and were highly focused on the assessment were more likely to have lower performance (Fincham et al., 2018; Matcha, Gašević, Ahmad Uzir, Jovanović, \& Pardo, 2019).

The studies presented thus far indicate that learning strategies can be derived from trace data and can be interpreted according to the theory of SRL and learning strategies (Maldonado-Mahauad et al., 2018; Fincham et al., 2018; Jovanović et al., 2017). However, whether the same analytics-based tactic and strategy detection methods are applicable across different learning designs and modalities remains questionable since how general the applied methods are has not been examined. As highlighted by Baker (2019), generalizability remains a big challenge in the field of learning analytics. Generalizability is difficult to achieve because applying the same methodology to different learning contexts may produce different results. This inconsistency was observed, for example, in a study by Gašević, Dawson, Rogers, and Gašević (2016). The study aimed to explore the factors that contributed to the success of nine undergraduate courses offered in BL modes. Gašević et al. (2016) found that 
the variables that were significantly predictive of academic performance in one course were not significantly predictive when applied to another course. This effect was due to the diversity of course instructional designs. On the other hand, replicating an analytics method across different learning contexts is essential for the method to reach maturity and acceptance. However, research focused on examining the general applicability of learning analytics methods is still limited (Gašević, Kovanović, \& Joksimović, 2017).

To our knowledge, no studies have investigated how applicable a data analytic approach is to the detection of learning tactics and strategies across different learning contexts. Therefore, the goal of this study is to explore whether the method proposed in our recent work (Matcha, Gašević, Ahmad Uzir, Jovanović, \& Pardo, 2019) is applicable across different learning contexts and to identify general factors that may have contributed to the choices of learning tactics and strategies based on well-defined educational theories. As such, the first research question has been defined as follows:

RQ1: Given a sequence of learning actions across several time frames, can we detect theoretically meaningful learning tactics and strategies applied by students when interacting with online learning activities across different course designs that are based on different delivery modalities?

\subsection{Learning Strategy and Academic Performance}

Learning strategies have an impact on learning performance (Winne, 2006; Yip, 2007). Research has found that not all students use effective learning strategies (Dunlosky, 2013; Malmberg et al., 2014). Research in traditional classrooms has found that low- and high-performing students tend to apply different learning approaches (DiFrancesca, Nietfeld, \& Cao, 2016; Proctor, Prevatt, Adams, Reaser, \& Petscher, 2006). For instance, Nandagopal and Ericsson (2012) found that upper-level college students were regulating their learning strategies differently. Students with higher performance engaged more in applying a variety of learning strategies and had a higher tendency to review lessons. DiFrancesca et al. (2016) used self-reports to capture students' perception of important learning strategies. They classified learning strategies into "less effective" (e.g., repeating words, attending class, and reading the textbook), "effective" (e.g., elaboration and connections, finding themes or main ideas, and application), and "help-seeking." Based on self-reports, they found that low-performing students perceived less effective learning strategies as more important than effective learning strategies and relied more on less effective strategies during their learning process. Being based on an instructional approach that is substantially different from those of the traditional classroom, current technology-enhanced learning contexts could impose further challenges for regulation of learning and selection of effective strategies. Therefore, how students regulate their learning strategies and how that regulation is associated with their academic performance might differ across different learning contexts.

In the FC setting, Gašević, Mirriahi, Dawson, and Joksimović (2017) explored the association between learning strategies detected from trace data with data analytic methods and approaches to learning reported by students and how the detected learning strategies were associated with students' academic performances. They found that students who reported using the deep approach to learning tended to have significantly higher learning performance. Broadbent and Poon (2015) conducted a literature review to investigate the relationship between SRL strategies and academic performance of online learners. They found that four learning strategies, namely meta-cognition, time management, effort regulation, and critical thinking, were significantly associated with course grades. Broadbent (2017) further explored the differences in self-reported SRL strategies across two different learning contexts, namely online learning and BL. She found that the time management strategy and the effort regulation strategy were significantly correlated with higher performance in online learning settings. In BL settings, however, elaboration, organization, meta-cognition, time management, and effort regulation strategies were found to be significantly correlated with higher academic performance. Broadbent (2017) observed that students who reported high frequency of using the rehearsal strategy were more likely to get a lower grade across two learning contexts. Students also reported a low frequency of using the peer-learning and help-seeking strategies in online learning. Finally, Broadbent (2017) recognized the drawbacks of using self-reports to obtain information about students' learning strategies, mainly that students might not be able to recognize that they used certain strategies.

The studies presented so far have demonstrated the differences in the association between learning strategies used and academic performance across different learning contexts. However, the association of learning strategies and academic performance across different course designs and delivery modalities has remained insufficiently explored. Moreover, the majority of the extant research on this association has relied on self-reports for collecting information about students' learning strategies. To our knowledge, limited research reported in the literature has explored the association between students' actual learning strategies (i.e., strategies derived from the learning activity records in a learning platform) and academic performance across different course designs and modalities. Therefore, our second research question is formulated as follows:

RQ2: Is there an association between learning strategies automatically detected with data analytic methods from trace data and students' academic performance in different course designs that are based on different delivery modalities? 


\section{Methods}

\subsection{Data}

\subsubsection{Description of the Data Sets}

Three data sets collected from three different learning contexts were used in this study. Table 1 briefly summarizes the learning contexts, and Table 2 summarizes the trace data sets collected in the three contexts. The data sets used in this study originate from different disciplines: two engineering courses and one science course. The structure and design of the courses were different. Table 3 offers a glimpse into the activities' structure by presenting percentages of learning activities as observed in the trace data.

Table 1. Summary of the Learning Context

\begin{tabular}{|c|c|c|c|c|c|}
\hline Dataset & Course & Modality & Years & $\begin{array}{l}\text { Course } \\
\text { Duration }\end{array}$ & Learning Activities \\
\hline DatasetA & $\begin{array}{l}\text { Computer } \\
\text { engineering }\end{array}$ & FC & 2014-2016 & 13 weeks & $\begin{array}{l}\text { Lecture videos, reading ma- } \\
\text { terials, quiz, exercises }\end{array}$ \\
\hline DatasetB & Biology & $\mathrm{BL}$ & 2016-2017 & 13 weeks & $\begin{array}{l}\text { Reading materials, pre-lab } \\
\text { external tools, revision tools, } \\
\text { quiz }\end{array}$ \\
\hline DatasetC & $\begin{array}{l}\text { Introduction } \\
\text { to Python }\end{array}$ & MOOC & 2018 & 8 weeks & $\begin{array}{l}\text { Lecture videos, reading ma- } \\
\text { terials, quiz, summative as- } \\
\text { sessment }\end{array}$ \\
\hline
\end{tabular}

Table 2. Summary of the Collected Trace Data

\begin{tabular}{lllll}
\hline Activities & Items & DatasetA & DatasetB & DatasetC \\
\hline Learning Activities & Lecture videos & Yes & - & Yes \\
& Quizzes embedded in the lecture videos & Yes & - & Yes \\
& Reading materials & Yes & Yes & Yes \\
& Quizzes embedded in the reading mate- & Yes & - & - \\
& rials & & & Yes \\
& Coding & - & - & Yes \\
& Conceptual quizzes & Yes & - & Yes \\
& Practical exercises & Yes & - & - \\
& Pre-lab activity & - & Yes & - \\
& Links to external tools & - & Yes & Yes \\
Learning Supports & Discussion forum & Yes & Yes & - \\
& Course structure/overview/syllabus & Yes & Yes & - \\
& Dashboard & Yes & - & - \\
\hline
\end{tabular}

DatasetA: The data set was collected in a first-year computer engineering course that was organized based on an FC model and offered at an Australian university. The study examined data from three successive course editions, in 2014, 2015, and 2016. The number of enrolled students steadily increased over the three years $\left(N_{2014}=290, N_{2015}=368\right.$, and $\left.N_{2016}=477\right)$. In all years, the course was scheduled for 13 weeks, with 10 topics studied.

Students were required to complete online pre-class learning activities and attend face-to-face classes. The current study focused on the online preparation activities, which were crucial for the success of the overall FC design (Rahman et al., 2015). Students were provided with a set of lecture videos, reading material, multiple-choice questions (MCQs) embedded in both video and reading material, and problem-solving exercises. The details of instructional design are provided by Pardo and Mirriahi (2017), Pardo et al. (2018), and Matcha, Gašević, Ahmad Uzir, Jovanović, and Pardo (2019).

Aside from learning activities, students were required to do a project. They were also provided with feedback. Two types of feedback were introduced over the three years: personal dashboards and analytics-based feedback in the form of personalized emails. The final assessment score of each student was determined by the completed problem-solving exercises during weekly preparation (20\%), a laboratory report (5\%), a laboratory project (15\%), the midterm exam in week $6(20 \%)$, and the final exam in week 13 (40\%) (Pardo et al., 2018). 
DatasetB: The second set of data was collected in an introduction to biology course offered to first-year students at an Australian university (different from the university where DatasetA was collected). The data were collected over two years $\left(N_{2016}=255\right.$ and $\left.N_{2017}=232\right)$. The course was based on the BL approach, involving online weekly activities and face-to-face sessions. The course consisted of 13 learning weeks and covered 10 topics. Students were required to attend three face-to-face lectures and one tutorial per week. The course also included three obligatory workshops and seven sessions of obligatory laboratory practice. Students were required to prepare for laboratory practical sessions by completing the online activities offered through the learning management system (LMS). Students needed to complete these pre-lab activities in weeks 4 to 6 and weeks 9 to 12 .

Students were also provided with online learning activities aimed to support self-revision after face-to-face lectures. The main learning materials consisted of lecture materials, other useful information, and external learning tools. The LMS provided students with links to these learning tools. The assessments were conducted four times. Two of them were administered in weeks 7 and 13 in the form of quizzes that contributed $20 \%$ of the final score (10\% each). Practicals in the laboratories counted for $25 \%$ toward the final mark, and the final exam was 55\% of the final mark. Students were provided with forums on which to discuss the learning topics. In 2017, students received personalized messages as feedback during week 4 and week 9 . The feedback aimed to create awareness of an individual's learning progress, including attendance at face-to-face learning sessions, engagement with the self-revision tool, and performance on the course assessment.

DatasetC: The third set of data was collected from an introduction to Python MOOC offered by a university in Chile. The course was delivered fully online via the Coursera MOOC platform. The trace data were collected for one course offering in $2018\left(N_{2018}=368\right)$. The seven-week course was self-paced and covered six programming topics. Each topic was divided into two or three subtopics. For each subtopic, a set of short video lectures with embedded questions (to provoke recollection of the concepts) and a set of reading materials (to support conceptual understanding) were provided. To support the practice of programming, students were required to complete two main learning tasks, namely conceptual exercises (11 quizzes) and practical exercises (13 tasks). Among the quizzes and tasks, 22 items were graded. Students were allowed to make multiple attempts on the quizzes, and the best scores were accumulated to calculate their final marks. Students were required to correctly solve at least $80 \%$ of these items to pass the course. The discussion forum was provided in the Coursera platform to support students' learning.

\subsubsection{Dataset Comparison}

Table 3 presents the proportion of learning activities captured in each data set. The proportion of learning activities reflects how students distributed their time and effort to complete the given learning tasks. The learning activities are categorized according to the Activity Type Framework (Olney, Rienties, \& Toetenel, 2018). The computer science and engineering courses (i.e., computer engineering and introduction to Python) relied heavily on practical exercises. In particular, in the Python course, students spent $80 \%$ of their effort practising by doing the available exercises. The distribution of student activities in the computer engineering course was rather diverse. Even though the majority of learning activities were focused on practical exercises $(42.25 \%)$, interaction with the videos was also well represented (25.14\%). Activities related to reading and conceptual quizzes had almost equal distributions of effort. The biology course structure was different from that of the other two courses. Students relied heavily on the reading materials $(44.88 \%)$. The pre-lab activities $(9.13 \%)$ served as the exercises to ensure that students prepared before their physical attendance at the laboratory sessions during weeks 4 to 6 and weeks 9 to 12 . Students participated in the discussion more often than in the other two courses (10.29\%).

\subsection{Data Analysis}

Learning sessions were extracted from trace data as sequences of consecutive learning actions by assuming that any two consecutive actions within a sequence were within $30 \mathrm{~min}$ of one another. The sequences varied, in terms of both length and composition of learning actions. To normalize the data, the outliers, that is, overly short sequences (consisting of one action) and overly long sequences (above the 95th percentile of the number of learning actions), were removed following the approach proposed by Jovanović et al. (2017). As a result, DatasetA contained 65,710 learning sessions. The length of learning sequences ranged from 2 to 175 actions. DatasetB consisted of 25,648 learning sessions, ranging from 2 to 47 actions. DatasetC contained 5,281 learning sessions and comprised 2 to 359 learning actions.

\subsubsection{Detection of Students' Learning Tactics and Strategies}

Figure 1 illustrates the pipeline of the analytic techniques used in this study. The first step in the pipeline is the detection of learning tactics using learning sessions as the input. A learning tactic can be considered as a sequence of actions that a student performs to complete the specified task (Fincham et al., 2018; Hadwin et al., 2007). To automatically detect learning tactics from learning sessions and address research question RQ1, we began by inspecting the learning process through a process-mining lens. Process mining generates a process model based on a set of time-stamped actions. By observing the overall process model, the potential number of learning tactics could be inferred based on the density of connections among 
Table 3. Proportion of Learning Activities Collected from each Dataset According to the Activity Types Framework Adapted from Olney et al. (2018)

\begin{tabular}{|c|c|c|c|c|c|}
\hline Activity Types & Description & Actions & $\begin{array}{l}\text { DatasetA: } \\
\text { FC Mode } \\
(100 \%)\end{array}$ & $\begin{array}{l}\text { DatasetB: } \\
\text { BL Mode } \\
(100 \%)\end{array}$ & $\begin{array}{l}\text { DatasetC: } \\
\text { MOOC } \\
\text { Mode } \\
(100 \%)\end{array}$ \\
\hline \multirow[t]{5}{*}{ Assimilative } & Attending to information & Home and updates & 6.05 & 28.17 & - \\
\hline & & Metacognitive - orientation & 0.96 & 1.25 & - \\
\hline & & Lecture videos & 25.14 & - & 3.7 \\
\hline & & Reading materials & 11.5 & 44.88 & 0.34 \\
\hline & & Links to external tools & - & 4.73 & - \\
\hline $\begin{array}{l}\text { Finding and } \\
\text { handling } \\
\text { information }\end{array}$ & $\begin{array}{l}\text { Searching for and processing } \\
\text { information }\end{array}$ & Utility function & 0.69 & 1.55 & - \\
\hline Communication & $\begin{array}{l}\text { Discussing module-related } \\
\text { content }\end{array}$ & Discussion forum & - & 10.29 & 0.05 \\
\hline Productive & $\begin{array}{l}\text { Actively constructing an arte- } \\
\text { fact }\end{array}$ & Code execute & - & - & 4.09 \\
\hline Experiential & $\begin{array}{l}\text { Applying learning in a real- } \\
\text { world setting }\end{array}$ & Workshop/lab & $\mathrm{F} 2 \mathrm{~F}$ & $\mathrm{~F} 2 \mathrm{~F}$ & - \\
\hline $\begin{array}{l}\text { Interactive/ } \\
\text { adaptive }\end{array}$ & $\begin{array}{l}\text { Applying learning in a simu- } \\
\text { lated setting }\end{array}$ & Pre-lab activities & - & 9.13 & - \\
\hline \multirow[t]{3}{*}{ Assessment } & All forms of assessment & $\begin{array}{l}\text { Conceptual quizzes (including } \\
\text { quizzes embedded in the lec- } \\
\text { ture videos and reading mate- } \\
\text { rial) }\end{array}$ & 12.08 & - & 11.09 \\
\hline & & Practical exercises & 42.25 & - & 80.73 \\
\hline & & Metacognitive - evaluation & 1.32 & - & - \\
\hline
\end{tabular}

actions. Process mining was performed using FOMMs as implemented in the pMineR R package (Gatta, Lenkowicz, Vallati, \& Stefanini, 2017). The output of a FOMM is an adjacency matrix of transition probabilities between events (i.e., learning actions). This output is suitable for cluster analysis using the EM algorithm (Ferreira \& Gillblad, 2009). Thus, EM was used to cluster learning sequences to detect meaningful learning tactics.

According to Derry (1989), a learning strategy employs one or more tactics. Therefore, learning strategies can be inferred from the way individuals employ tactics. Hence, in the second step, the agglomerative hierarchical clustering based on Ward's algorithm (Gabadinho, Ritschard, Studer, \& Muller, 2008) was used to extract patterns of how individual students used the identified learning tactics. As the input for the clustering process, for each student, we used the number of each identified tactic and the total number of all tactics. The Euclidean metric was used to calculate the (dis)similarity between vectors of the input. A dendrogram was used to determine the optimal number of clusters. This process, based on hierarchical clustering, has already been established for the detection of learning strategies (Jovanović et al., 2017; Kovanović, Gašević, Joksimović, Hatala, \& Olusola, 2015).

\subsubsection{Exploring the Detected Learning Tactics and Strategies}

Patterns detected in the trace data require content-based interpretation to provide actionable insights (Maldonado-Mahauad et al., 2018; Pardo et al., 2018). To understand the characteristics of the detected clusters (i.e., tactics and strategies) and further address research question RQ1, sequence analysis and process mining were used. The TraMineR R package allows for constructing and examining sequences of actions (Gabadinho et al., 2008). It can be used to explore the frequency, the ordering, and the distribution of actions within sequences, and to explore clusters of sequences.

The pMineR R package (Gatta et al., 2017) was also used to explore the temporal characteristics of the learning strategy groups. Specifically, in the computer science/engineering and biology courses, we analyzed changes of learning tactics for each strategy group within each week of the course. We decided to use the week as the unit of analysis given the weekly activity cycles in those courses, as is common in formal higher-education settings (Pardo et al., 2018). But in the self-paced learning course (i.e., introduction to Python), it was more meaningful to explore the changes in tactics at the level of learning topics 

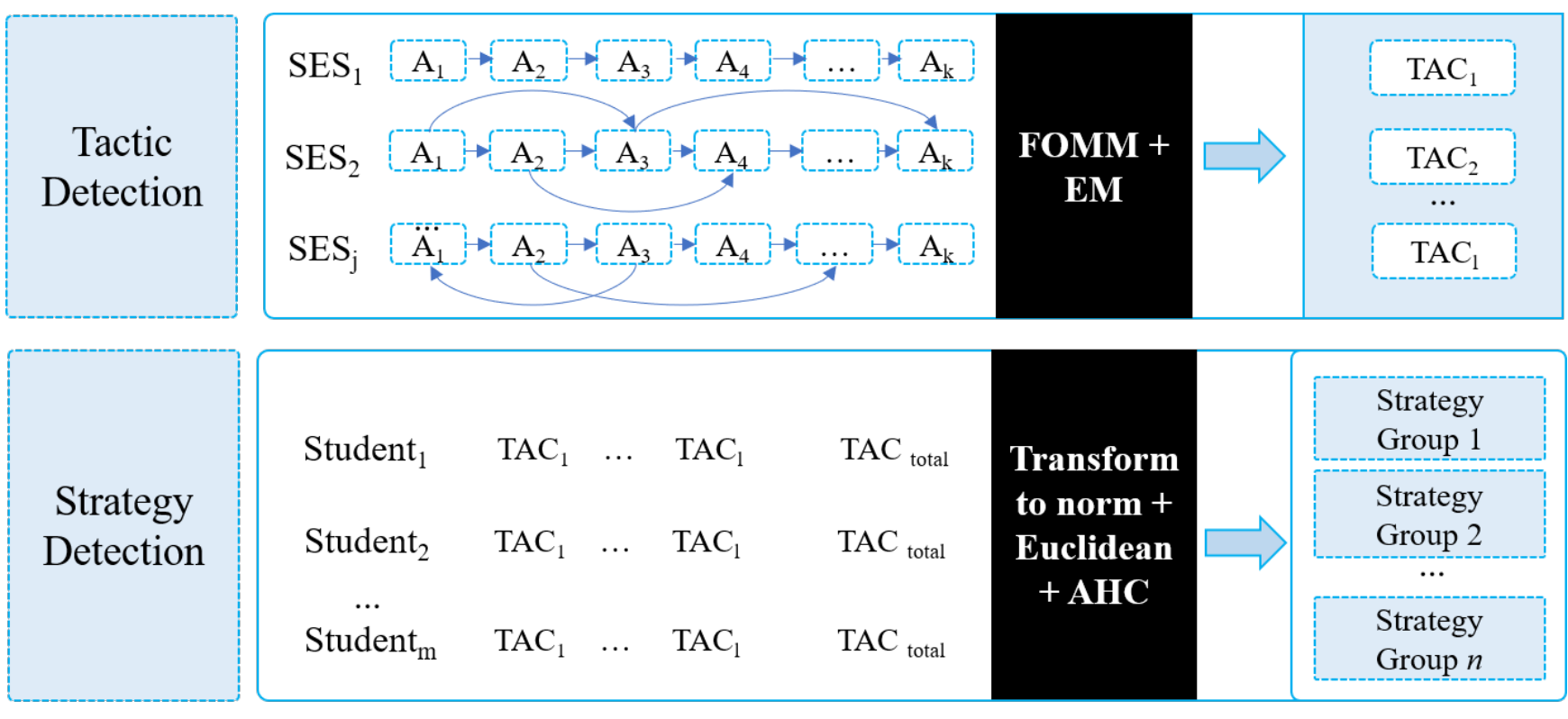

(*SES: Learning Session; A: Learning Action; FOMM: First Order Markov Model; EM: Expectation-Maximization; AHC: Agglomerative Hierarchical Clustering; TAC: Learning Tactic)

Figure 1. Learning Tactics and Strategies Detection Process (Matcha, Gašević, Ahmad Uzir, Jovanović, Pardo, Maldonado-Mahauad, \& Pérez-Sanagustín, 2019)

because students were studying at their own pace and thus the schedules of individual students differed.

\subsubsection{Association with Academic Performance}

Descriptive and inferential statistics were used to characterize the identified clusters (i.e., tactics and strategies). Kruskal-Wallis tests were used to examine the association between learning strategies and course performance to address research question RQ2.

\section{Results}

\subsection{RQ1: Detection of Learning Tactics and Strategies}

4.1.1 Detection of Learning Tactics from Trace Data

Computer Engineering Course. Figure 2 presents the overall state distribution and state distribution in each year for the five detected tactics in the computer engineering course. The supplementary document that can be found online ${ }^{1}$ presents the details of the detected learning tactics. Each tactic was labelled according to the characteristics of the detected patterns by considering the state distribution, ordering of sequences, frequency, and length of the sequences.

The five detected tactics can be summarized as follows:

- Diverse $(N=8,288,12.61 \%$ of all sequences): This tactic was characterized by the longest sequences of learning actions (median $=53$ actions per sequence). The adoption of this tactic meant a variety of actions, with a relatively even distribution of exercises, MCQs, and video views.

- Reading oriented ( $N=17,024,25.91 \%)$ : The sequences of learning actions were the shortest in this tactic (median $=4$ actions in a sequence). The dominant kind of action was access to the reading materials. Similar patterns were observed across the three years of data collected.

- Exercise oriented ( $N=16,287,24.79 \%)$ : This tactic was characterized by a moderate number of learning actions (median $=24$ actions per sequence). The most dominant learning actions were correctly (EXE_CO) and incorrectly (EXE_IN) solving the exercise questions. Unlike other tactics, most of the learning sequences in this tactic began by direct access to the problem-solving activities rather than access to the reading materials (Refer to Table 1 in the supplementary document). This tactic was presented similarly across the three years.

\footnotetext{
${ }^{1}$ https://bit.1y/37bzbeB
} 

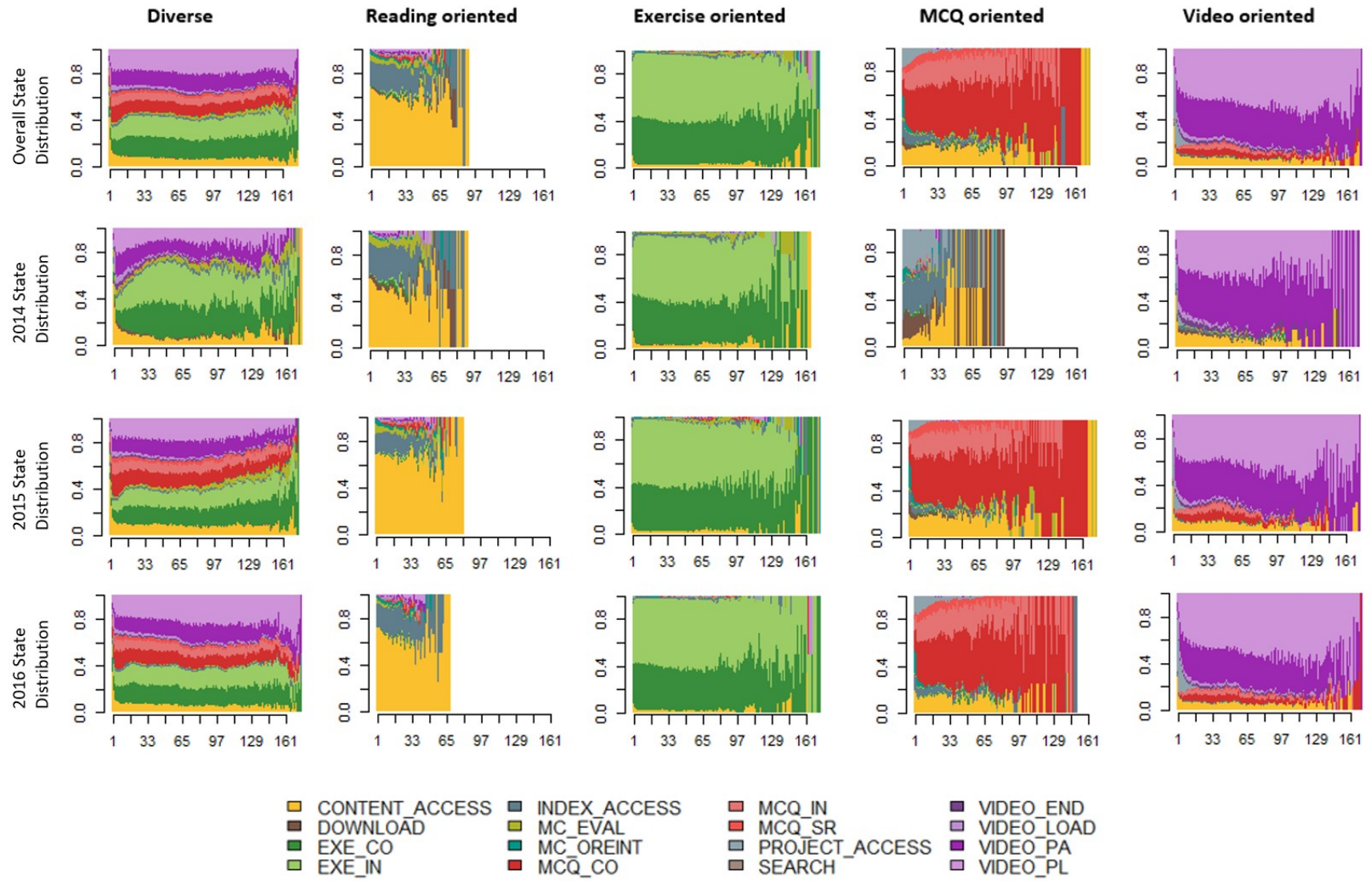

$\square$ SEARCH $-A C C E S S \square$ VIDEO_PL

Figure 2. Learning Tactics Detected from Trace Data Collected in the Computer Engineering Course

- MCQ oriented ( $N=11,915,18.13 \%)$ : Relatively short learning sessions were characteristic of this tactic (median $=5$ actions per session) that often began by accessing reading materials (CONTENT_ACCESS), followed by MCQ answering. MCQ-related actions, including correctly answering (MCQ_CO), incorrectly answering (MCQ_IN), and asking for help (MCQ_SR), were the most dominant type of action. These learning tactic patterns were present in 2015 and 2016. However, in 2014, the most dominant actions were accessing the index, project, and other learning content rather than MCQ access. This is due to the proportion of MCQ-related interaction collected in trace data for 2014 being much lower than in 2015 and 2016.

- Video oriented $(N=12,196,18.56 \%)$ : This tactic was associated with relatively short sessions (median $=9$ actions per session). Based on the sequence length and dominant type of action, two types of learning sequences could be distinguished (Table 2). Long sessions often comprised content access followed by video-playing/pausing actions, which were in turn followed by MCQ-related actions (refer to Table 1 in the supplementary document). Shorter sessions consisted mainly of access to the project information pages. Similar behaviours were observed across the three years.

Overall, metacognitive actions, which consisted of access to the dashboard (MC_EVAL) and course syllabus (MC_ORIENT), were noticeable in every tactic but showed relatively low presence compared to other types of actions (Figure 2 and Table 1 in the supplementary document) $)^{2}$.

Biology Course. Three learning tactics were detected from the trace data collected in the biology course. Figure 3 shows the overall state distribution and yearly state distribution of learning actions in each detected tactic. In general, the lengths of the learning sessions were relatively short.

- Reading oriented ( $N=11,358,44.28 \%$ of all sequences): This tactic is characterized by relatively short learning sessions (median $=5$ actions per session). The most dominant learning action was access to the reading materials and home page, which contained general information about the course. Other types of learning actions were hardly observed. This tactic was observable across the two years of collected data.

\footnotetext{
${ }^{2}$ https://bit.ly/37bzbeB
} 

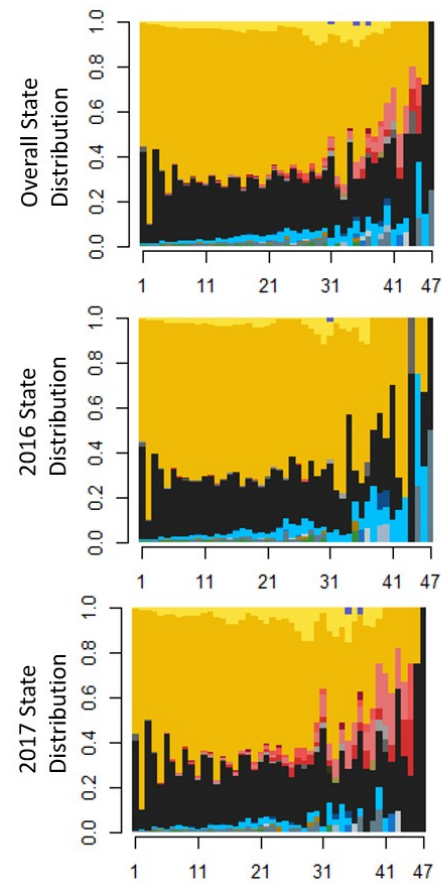
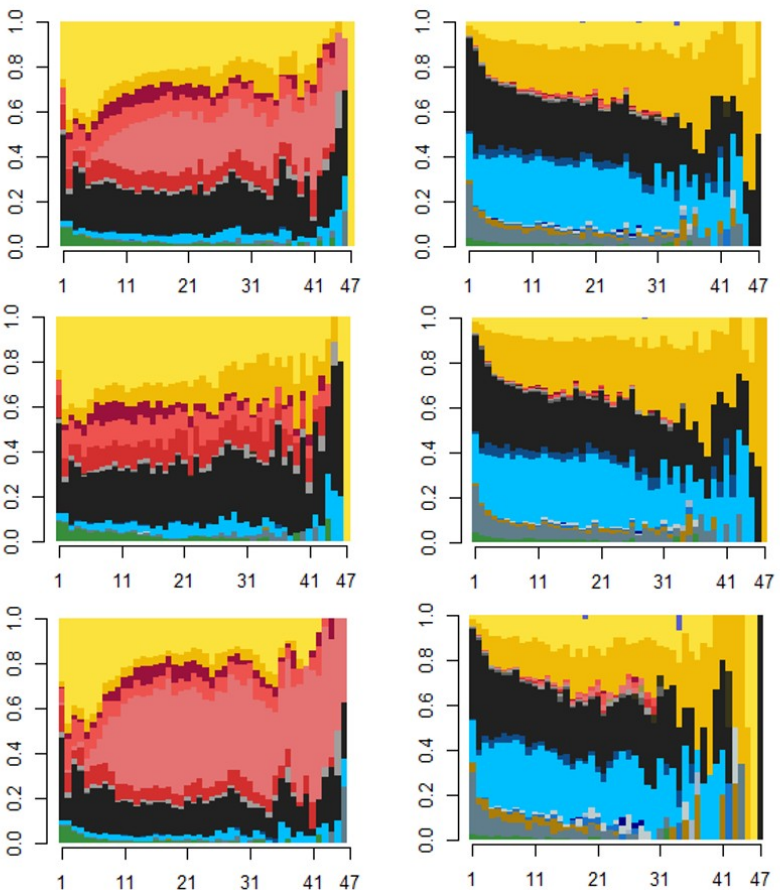

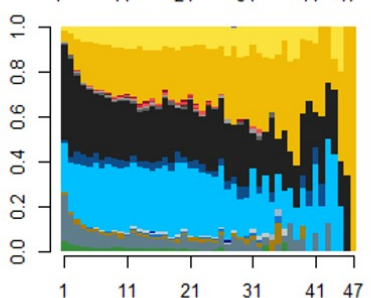

Assignment Submission: Status

Connect: Access

$\square$ Connect: Register

$\square$ Discussion: Create

$\square$ Discussion: Delete

$\square$ Discussion: Post

- Discussion: Update

$\square$ Discussion: View

Discussion: View News and Update

- Home Page: Access

- MetaCog: View Course Outline

MetaCog: View Course Structure

$\square$ Other: Print

$\square$ Other: Search

$\square$ Pre-Lab: Launch

$\square$ Pre-Lab: Submit

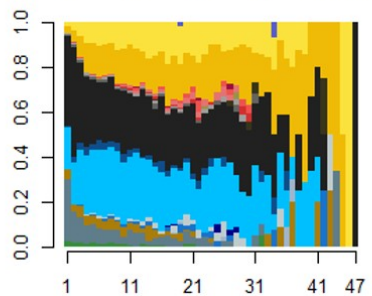

Pre-Lab: View

$\square$ Pre-Lab: View Status

$\square$ Reading: Lecture Materials

$\square$ Reading: Useful Information

$\square$ YourTutor: Access

Figure 3. Learning Tactics Detected from Trace Data Collected in the Biology Course

- Reading and pre-lab oriented $(N=4,287,16.71 \%)$ : The sessions grouped in this tactic were the longest (median $=9$ actions). The most dominant learning actions included access to the external reading materials and the course homepage, as well as those related to preparing for the laboratory practice. In 2016, the interactions with pre-lab activities were slightly lower than in 2017.

- Reading and discussion oriented ( $N=10,003,39.00 \%)$ : This tactic is characterized by very short learning sessions (median $=4$ actions). The most frequently observed learning actions in this tactic were accessing the course homepage and other course pages, viewing the discussion forum, and accessing the external revision tool. The patterns of this tactic were similar for both years.

Introduction to Python Course. Four learning tactics were detected from the trace data collected from the introduction to Python course. Figure 4 shows the state distribution of learning actions for each detected tactic.

Diverse-Practice Oriented

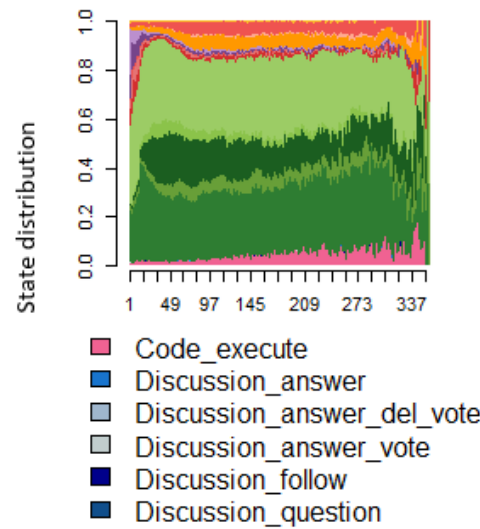

Lecture Oriented

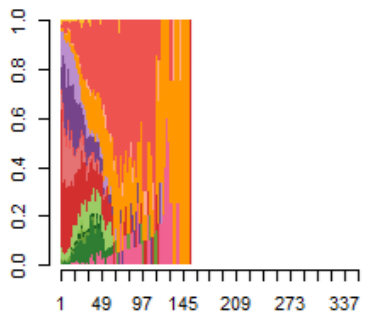

$\square$ Discussion_question_vote

$\square$ Discussion_unfollow

$\square$ exam

$\square$ exam complete

$\square$ exam_correct

$\square$ exam_incorrect
Short-Practice Oriented

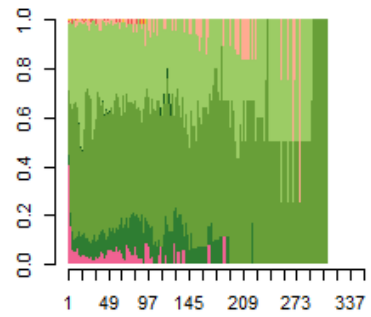

$\square$ exam_start

$\square$ in video quiz

$\square$ in_video_quiz_correct

$\square$ in_video_quiz_incorrect

$\square$ lecture_complète

$\square$ lecture start

Figure 4. Learning Tactics Detected from Trace Data Collected in the Introduction to Python Course 
- Diverse-practice oriented ( $N=2,000,37.87 \%$ of all sequences): Each learning session contained a variety of learning actions. The learning sessions were quite long (median $=105$ actions per session). The most dominant learning actions were practical exercises. Other types of learning activities, such as quizzes, code execution, and video lectures, were also observed.

- Lecture oriented ( $N=1,391,26.34 \%)$ : This tactic gathered short learning sessions (median $=7$ actions), where students primarily interacted with the video lectures and answered the embedded quizzes. Interactions with the theoretical quizzes were also observed.

- Short-practice oriented ( $N=772,14.62 \%$ ): This tactic is characterized by short learning sessions (median $=8$ actions). The most dominant learning actions were executing the code and performing practical exercises, as shown in Figure 5.

- Long-practice oriented $(N=1,118,21.17 \%)$ : This tactic exhibited a similar pattern as in the short practice-oriented tactic; that is, code execution and practical exercises (i.e., correctly or incorrectly solving the exam questions) were the most dominant learning actions. However, the learning sessions (median $=31$ per session) were longer than those within the short practice-oriented tactic. Figure 5 illustrates all learning sequences categorized as short practice- and long practice-oriented tactics. Alternation between correctly and incorrectly solved exercises and code execution was commonly observed in the long practice-oriented tactic. The short practice-oriented tactic contained two different patterns of practice-related actions: (i) very short sessions of code execution and (ii) relatively long sessions of work on the practical exercises.

\section{Short-Practice Oriented}
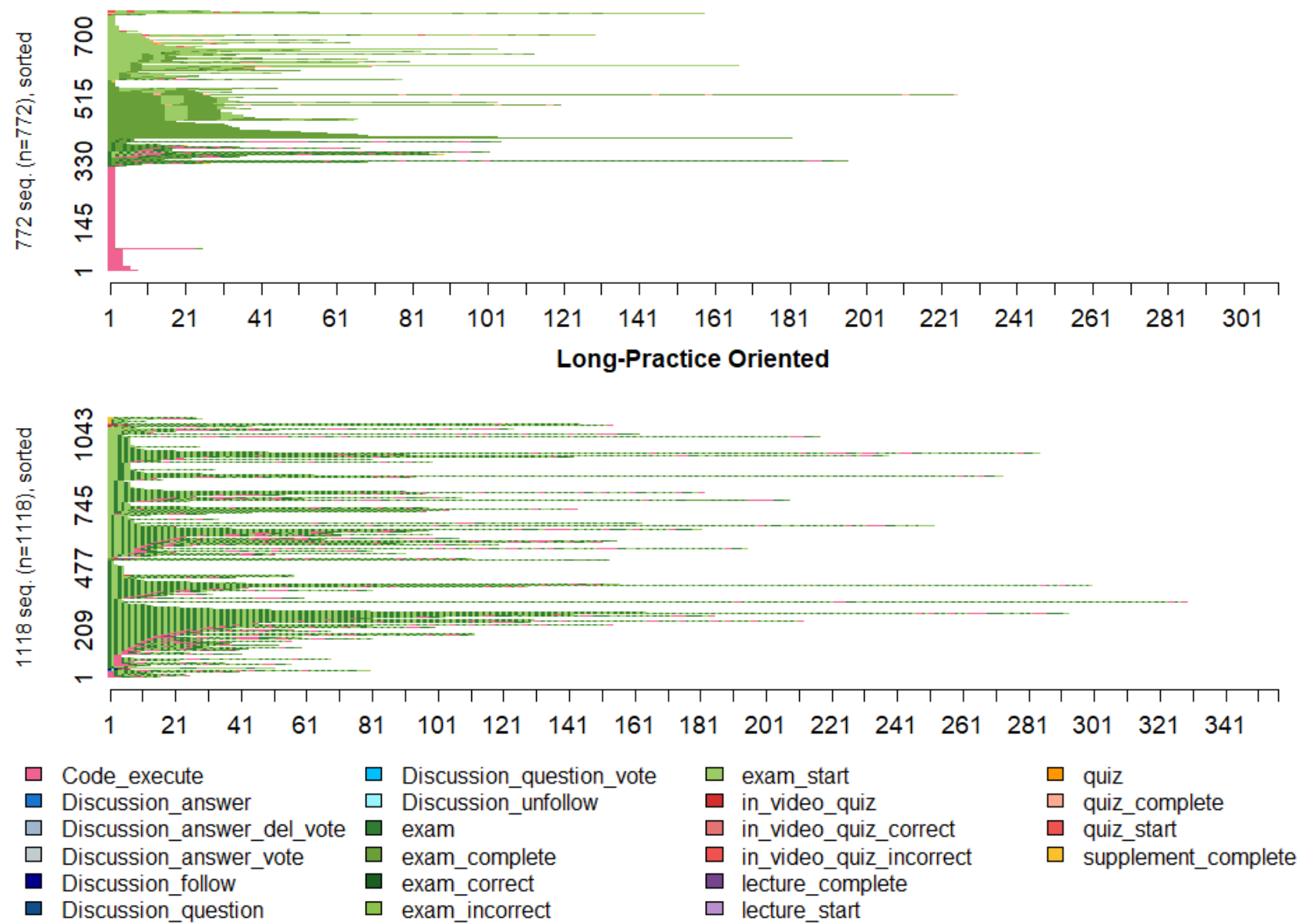

Figure 5. Different Learning Actions between Short and Long Practice-Oriented Tactics in the Introduction to Python Course 


\subsubsection{Detection of Learning Strategies from Learning Tactics}

Computer Engineering Course. The dendrogram produced by the employed clustering algorithm suggested three strategies as the best solution. Table 4 presents the summary statistics for the variables that served as the input for the clustering: the number of times each of the learning tactics was used as well as the overall number of learning tactics per student. To better understand the detected learning strategies, we also examined, for each strategy, how the use of learning tactics changed throughout the course. Figure 6 illustrates overall and yearly patterns of each detected strategy group by presenting the median numbers of tactics applied in each week of the course.

Strategy Group 1: Strategic - Moderate Engagement: This was the largest cluster $(N=519,45.73 \%)$. Students in this strategy group tended to use different learning tactics in different weeks of the course. Only the exercise-oriented tactic was consistently used throughout the semester across the three years of the courses included in this study. In the first half of the semester (week 2-week 6), in addition to exercises, students also focused on reading materials and the associated MCQs. These patterns were observed in 2014 and 2015. However, in 2016, students applied a lower frequency of the reading tactic than in the other two years. In the second half of the semester (weeks 7-13), the exercise-oriented tactic was combined with the video- and reading-oriented tactics.
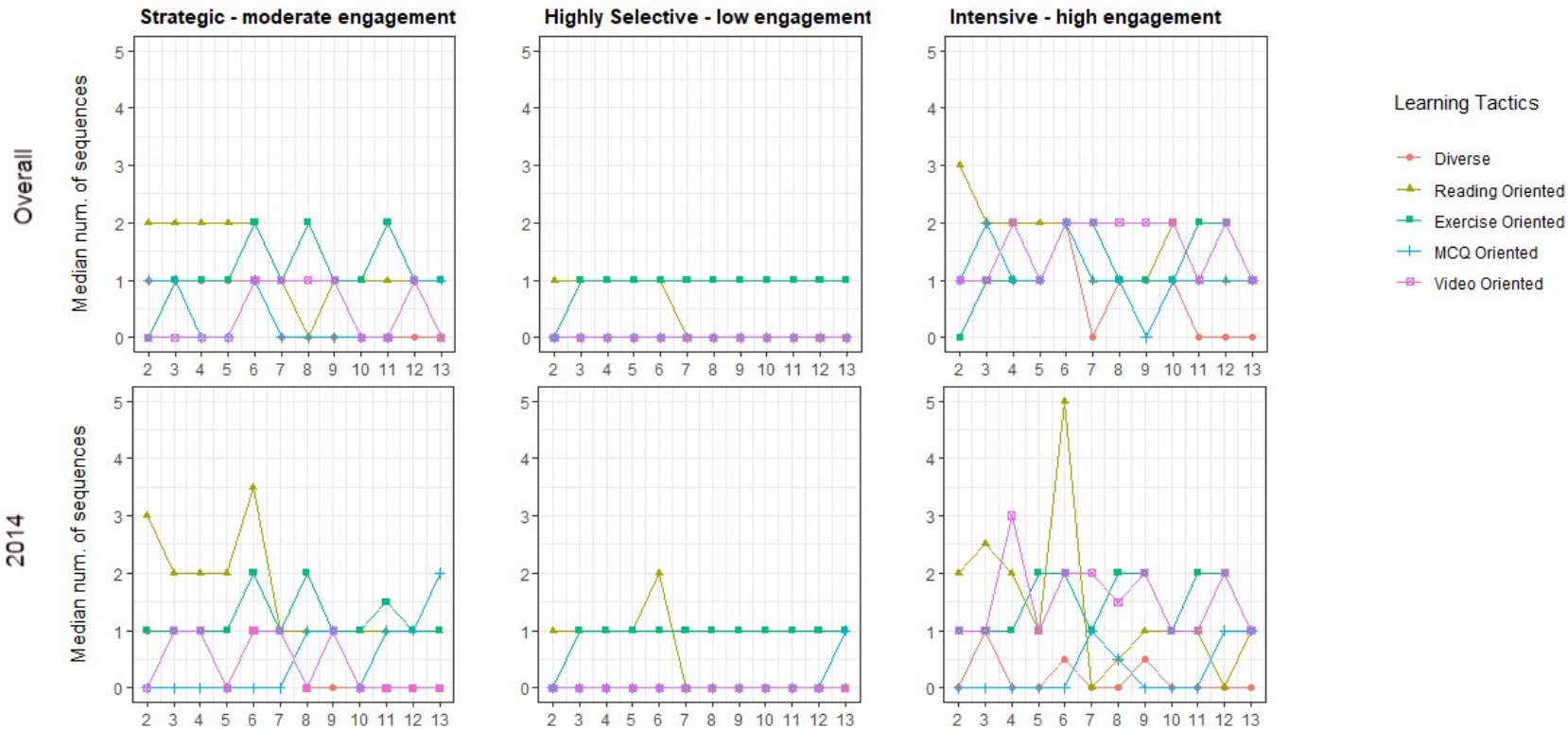

- Video Oriented
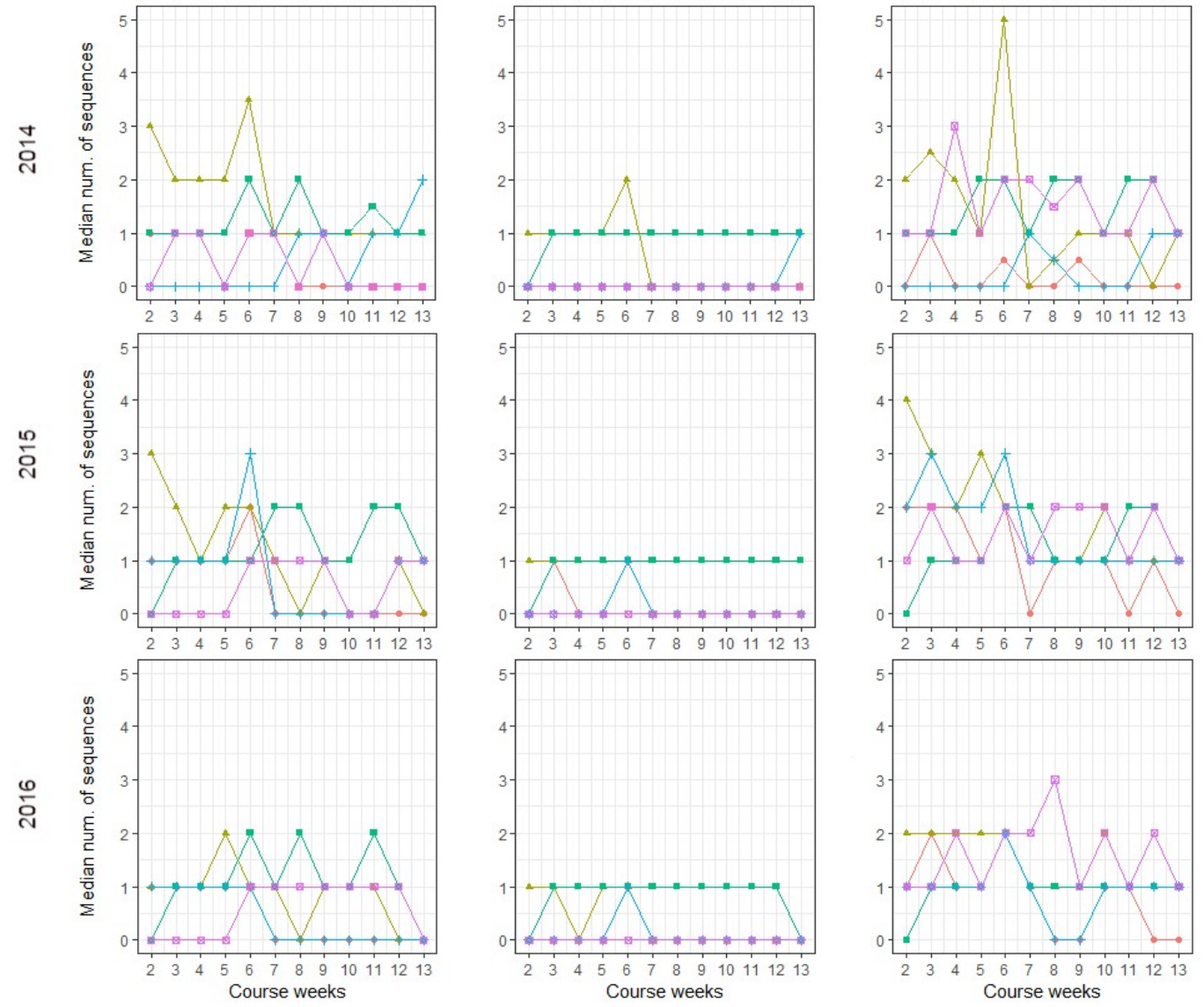

Figure 6. Learning Strategies Detected from Trace Data Collected in the Computer Engineering Course 
Table 4. Summary Statistics (median, first and third quartiles) for Variables Used to Detect Learning Strategies in the Computer Engineering Course

\begin{tabular}{llll}
\hline Tactics & Strategy 1 & Strategy 2 & Strategy 3 \\
\hline Diverse & $8.0(5.0-11.0)$ & $3.0(1.0-5.0)$ & $13.0(8.0-17.0)$ \\
Reading & $15.0(11.0-22.5)$ & $7.0(4.0-11.0)$ & $21.5(14.0-30.0)$ \\
Exercise & $15.0(12.0-18.0)$ & $12.0(9.0-15.0)$ & $17.0(13.0-20.0)$ \\
MCQ & $10.0(7.0-15.0)$ & $5.0(2.0-7.0)$ & $16.5(10.0-27.0)$ \\
Video & $11.0(8.0-14.0)$ & $4.0(2.0-6.0)$ & $23.0(19.0-27.0)$ \\
\hline Total & $62.0(53.0-72.0)$ & $33.0(25.0-41.0)$ & $94.5(77.2-111.0)$ \\
\hline
\end{tabular}

Strategy Group 2: Highly Selective - Low Engagement: The proportion of students in this strategy group was relatively high $(N=418,36.83 \%)$. Students in this group had low engagement with the preparation activities (Table 3 ). They chose to focus on specific types of learning tactics, namely, exercise and reading oriented. The exercise-oriented tactic was used throughout the semester, whereas the reading-oriented tactic was present only up until the midterm exam (week 6). This shallow regulation of learning tactics was consistently observed in all three years of collected data.

Strategy Group 3: Intensive - High Engagement: This was the smallest group $(N=198,17.44 \%)$, comprising students with the highest engagement level, especially in 2014. They applied a variety of learning tactics. The reading-, video-, MCQ-, and exercise-oriented tactics were used each week throughout the semester. The use of the diverse tactic was observed in certain weeks only (weeks 6 and 10), particularly in 2016. The diverse tactic was the most dominant tactic used.

To further our understanding of the detected learning strategies, FOMMs were fitted to explore transitions from one learning tactic to another within each learning strategy. Figure 7 presents the process models of each learning strategy based on the transition of tactics.

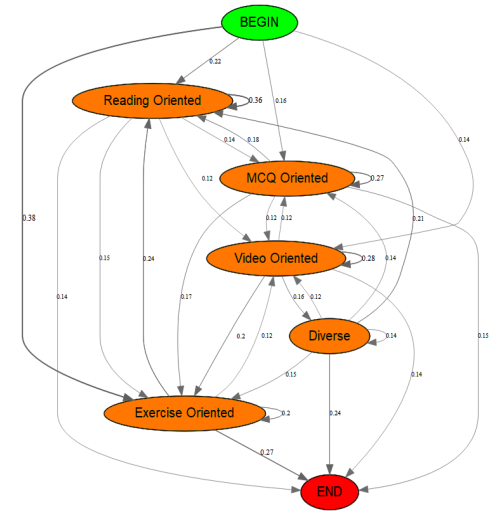

(a) Strategic - moderate engagement

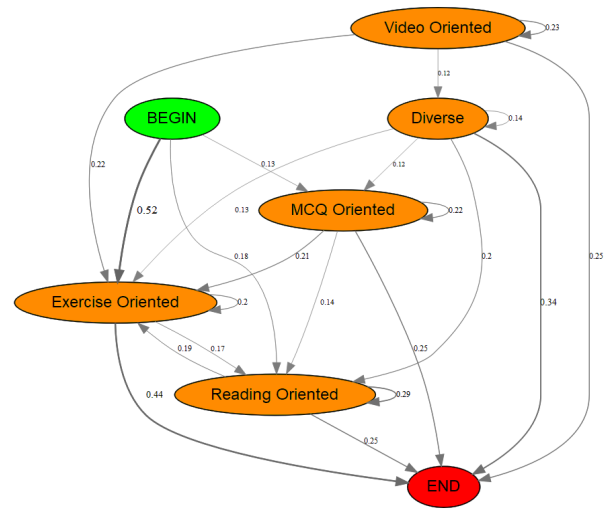

(b) Highly selective - low engagement

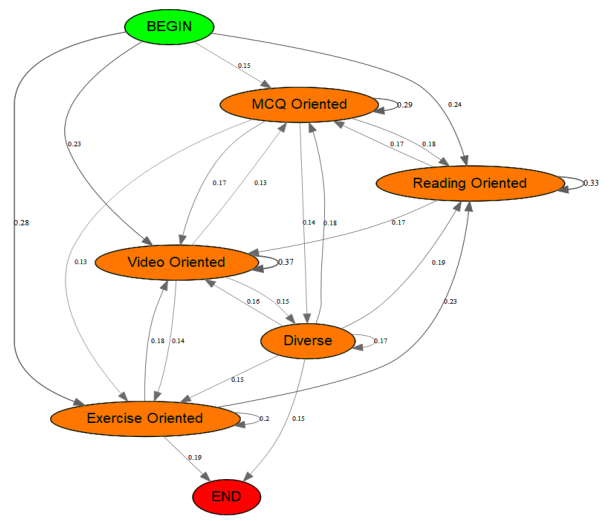

(c) Intensive - high engagement

Figure 7. The Process of Tactic Application on a Weekly Basis in the Computer Engineering Course 
Because the course was designed on a weekly basis, the process model of learning tactics application was built by using the weekly tactics applied by individual learners as the input. The main focus of the strategic - moderate engagement strategy was on the exercises. There was a high probability $(p=0.38)$ for students in this group to have weeks based on the exercise-oriented tactic. The second most frequently use tactic was reading oriented, which was observed with a lower probability $(p=0.22)$. When it comes to changing learning tactics from one session to another one within a week, the most notable were the shift from the exercise-oriented tactic to the reading-oriented tactic $(p=0.24)$ and the shift from the reading-oriented tactic to the diverse tactic $(p=0.21)$. The weeks often ended by using the exercise- and diverse-oriented tactics. The main characteristic of the highly selective - low engagement strategy was its concentration on the exercise-oriented tactic. There was a strong probability that students in this strategy group began and ended their weeks by doing exercises ( $p=0.52, p=0.44$, respectively). Students who adopted the intensive - high engagement strategy tended to begin their study weeks with a variety of learning tactics, rather than relying on one specific tactic. More precisely, the beginning of the week was almost equally distributed across the reading- $(p=0.24)$, exercise- $(p=0.28)$, and video-oriented tactics $(p=0.23)$. Transitions between learning tactics were clearly observable and roughly equally distributed (probabilities ranged from 0.15 to 0.23 ). This indicates that students in the intensive - high engagement group used a variety of learning tactics, which can be interpreted as an indication of their ability to regulate their learning (Winne, 2013).

Biology. The learning strategy groups were detected based on how students employed the tactics throughout the course. Similar to Figure 6, Figure 8 shows for each strategy group their weekly pattern in the use of learning tactics. Table 5 presents summary statistics (median, first and third quartiles) for the learning tactics used by each of the detected learning strategy groups.

Table 5. Summary Statistics (median, first and third quartiles) for Variables Used for Detecting Learning Strategies in the Biology Course

\begin{tabular}{llll}
\hline Tactics & Strategy 1 & Strategy 2 & Strategy 3 \\
\hline Reading & $40.0(28.0-52.0)$ & $25.0(17.0-34.0)$ & $12.0(7.0-19.0)$ \\
Reading and pre-lab & $13.0(10.0-17.0)$ & $11.0(8.0-13.0)$ & $5.0(3.0-7.0)$ \\
Reading and discussion & $44.0(34.0-53.0)$ & $20.0(14.0-26.0)$ & $10.0(6.0-16.0)$ \\
\hline Total & $95.0(82.5-112.0)$ & $57.0(49.0-65.0)$ & $32.0(21.5-40.0)$ \\
\hline
\end{tabular}

- Strategy 1: Intensive - High Engagement ( $N=79$ students, 16.22\%): These students were quite active. They employed a variety of learning tactics, especially the reading- and reading and discussion-oriented tactics. However, in 2017 the median number of reading tactic applications was lower than in 2016. As indicated by the high use of the reading and discussion tactic, students in this group were highly active in the discussion forum, especially during week 7 and week 13, when the midterm and final exams were scheduled. Students accessed the pre-laboratory activities throughout the study weeks.

- Strategy 2: Strategic - Moderate Engagement ( $N=193$ students, 39.63\%): Students in this group exhibited learning behaviours according to the course design. During weeks 4 to 6 and 9 to 12, students were required to prepare for the face-to-face lab by completing a set of activities before the session. Access to lab activities was observed particularly during these weeks and it was invisible when it was not required. Meanwhile, the reading tactic was used at least once a week. The reading and discussion tactic was also observed, and its use peaked in week 6 when the midterm exam was scheduled. The regularity of tactics application was similar for both 2016 and 2017.

- Strategy 3: Highly Selective - Low Engagement $(N=215$ students, 44.15\%): Students employed surface learning strategies in their online learning activities. In general, the learning activities were observed at the beginning of the course (weeks 1-4) and when the exams were scheduled (week 7 and week 13). The reading and discussion tactic was highly employed during the exam weeks. Preparation for the labs was not observed except for the first session in week 4. In 2017, the median number of tactics application was lower than in 2016.

The process model based on the transition of learning tactics is presented in Figure 9. In the intensive - high engagement strategy group, there was a high probability for students to begin the learning sessions by using the reading and discussionoriented and reading-oriented tactics ( $p=0.46$ and $p=0.38$, respectively). The probability of starting weekly learning sessions by using the reading and pre-lab tactics was very low $(p=0.16)$. The process model suggested that students would apply the reading-oriented or reading and discussion-oriented tactic after using the reading and pre-lab-oriented tactic $(p=0.30)$. There was almost an equal probability of transition between applying the reading and reading and discussion tactics. Unlike 

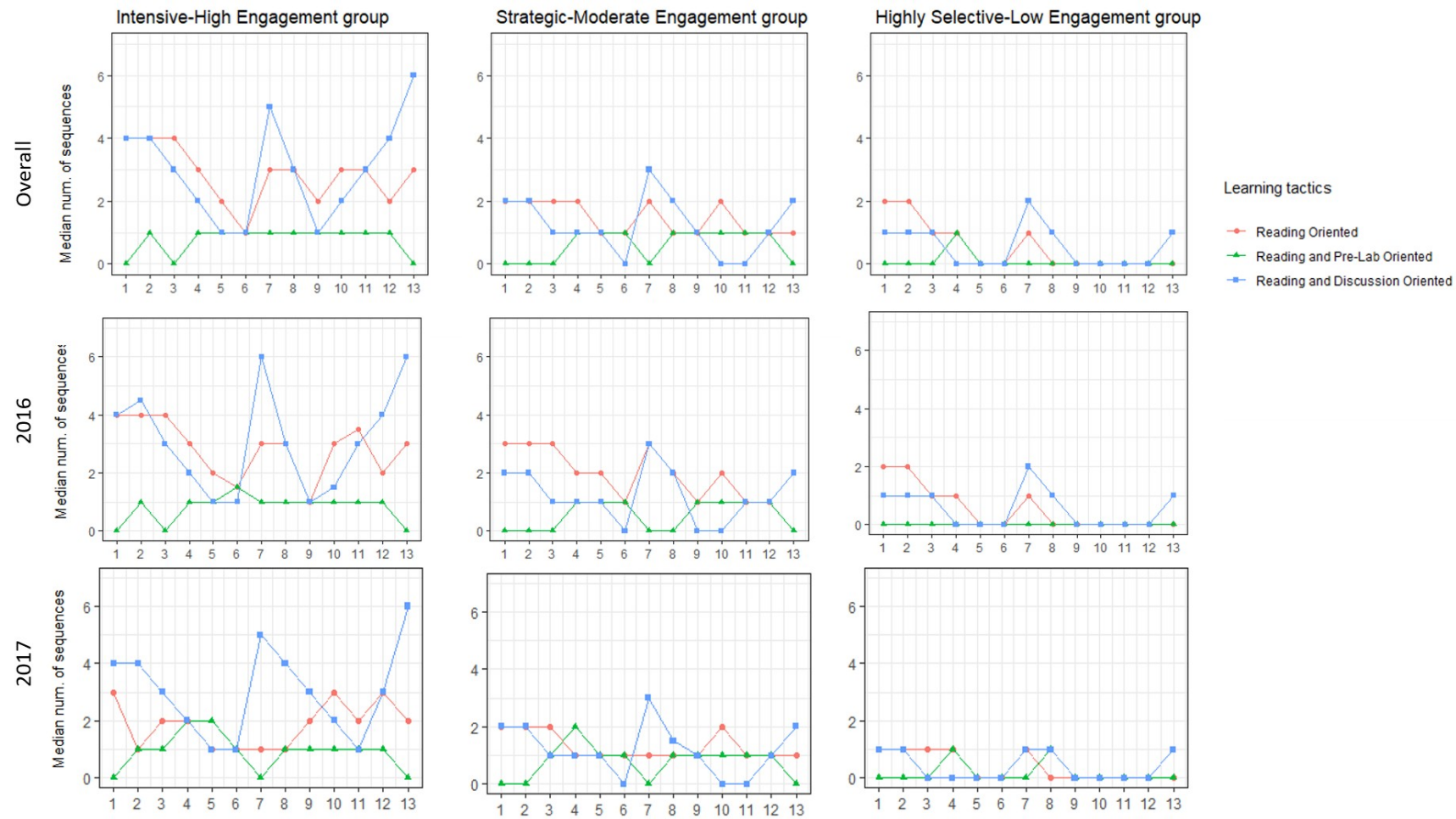

Course weeks

Course weeks

Figure 8. Learning Strategies Detected from Trace Data Collected in the Biology Course

the intensive - high engagement strategy group, the strategic - moderate engagement strategy group showed a strong probability of beginning weekly online learning by applying the reading-oriented tactic $(p=0.45)$ and repeatedly using this tactic $(p=0.45)$. The second most applied tactic was reading and discussion $(p=0.34)$. This strategy group had a higher probability of applying the reading and pre-lab tactics at the beginning of the week $(p=0.21)$ than the intensive - high engagement strategy group did. The highly selective - low engagement strategy group showed similar transitions as the intensive - high engagement strategy users did at the beginning of the weekly topics. They had a strong probability of beginning a study week by using the reading $(p=0.41)$ and reading and discussion-oriented tactics $(p=0.38)$. However, the transitions between tactics were less prominent than in the intensive - high engagement group. Students in this strategy group had a high probability of ending their weekly study after applying one learning tactic only.

Introduction to Python. The dendrogram suggested three learning strategy groups for the Python course. Table 6 shows summary statistics (median, first and third quartile) for the number of learning tactics used by each of the detected strategy groups.

Table 6. Summary Statistics (median, first and third quartile) for Variables Used for the Learning Strategies Detected in the Python Course

\begin{tabular}{llll}
\hline Tactics & Strategy 1 - Inactive & $\begin{array}{l}\text { Strategy 2 - Highly Active at the Begin- } \\
\text { ning }\end{array}$ & Strategy 3 - Highly Active \\
\hline Diverse & $4.0(2.0-7.0)$ & $7.0(4.0-11.0)$ & $14.0(11.0-20.2)$ \\
Lecture-Based & $2.0(0.5-3.0)$ & $8.0(7.0-11.0)$ & $5.0(2.0-9.2)$ \\
Short-Practice & $0.0(0.0-1.0)$ & $0.0(0.0-2.0)$ & $1.5(0.0-3.0)$ \\
Long-Practice & $1.0(0.0-3.0)$ & $2.0(1.0-3.0)$ & $9.0(7.0-13.0)$ \\
\hline Total & $8.0(5.0-13.0)$ & $20.0(15.0-28.0)$ & $29.5(25.0-44.5)$ \\
\hline
\end{tabular}

Unlike the other two learning modalities, where the learning schedules were fixed, the introduction to Python course, being delivered in a MOOC setting, offered a self-paced learning schedule. That is, students could begin and complete the learning activities in their own time. Therefore, the learning strategies were explored by focusing on the course topics rather than the course weeks.

ISSN 1929-7750 (online). The Journal of Learning Analytics works under a Creative Commons License, Attribution - NonCommercial -NoDerivs 3.0 Unported (CC BY-NC-ND 3.0) 


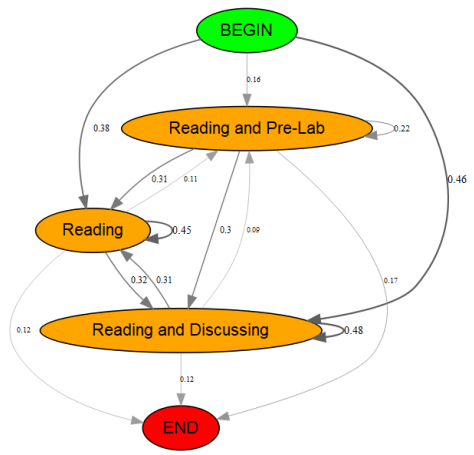

(a) Intensive - high engagement

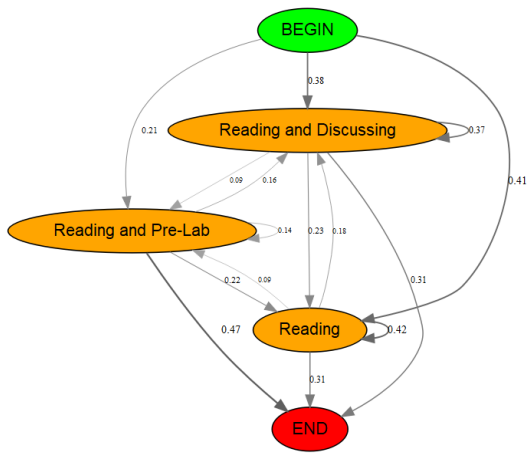

(c) Highly selective - low engagement

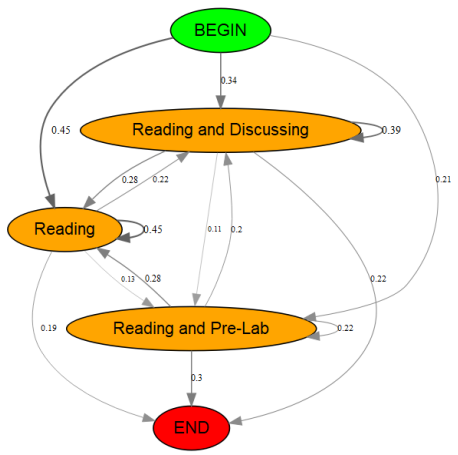

(b) Strategic — moderate engagement

Figure 9. The Process of Tactic Application on a Weekly Basis in the Biology Course

Figure 11 presents the average frequency of the four detected learning tactics according to the study topics.

- Strategy 1: Inactive ( $N=215$ students, 58.42\%): Students employed a low level of learning effort. A low level of engagement was observed in relation to each study topic. The most dominant learning tactic was the diverse tactic.

- Strategy 2: Highly active at the beginning ( $N=89$ students, $24.18 \%)$ : Students were highly active at the beginning of the course (first two topics). The amount of effort dropped after the second topic. The dominant learning tactics used were lecture and diversity oriented. One possible explanation for the observed behaviour is that students were not familiar with programming or were inexperienced in learning to program. Even though the course design was strongly oriented toward practical exercises (see Table 3), students strongly preferred the lecture-oriented tactic over the short and long practice-oriented tactics.

- Strategy 3: Highly active ( $N=64$ students, 17.39\%): Students were highly active. Multiple uses of different tactics were observed. The use of the long practice-oriented tactic increased as the course progressed. The short practice-oriented tactic was used at least once when interacting with each course topic but highly used during the fourth topic. Similarly, the diverse tactic was used at least once in each course topic but highly used when interacting with the third and fourth topics. The lecture-oriented tactic was also observed at least once for each learning topic.

The process model based on the tactics applied by each strategy group per each course topic of the Python course is presented in Figure 10. The central learning tactic used in the inactive strategy group was diverse-practice oriented. The inactive strategy users frequently used the diverse practice-oriented tactic at the beginning of interaction with each topic $(p=0.59)$ and at the end of their topic-related activities $(p=0.36)$. There was an observable common practice to begin interaction with each topic by using the lecture-oriented tactic, and end the topic-related activity by applying the diverse-practice tactic. A transition from applying the long-practice to diverse-practice tactics could also be observed $(p=0.35)$. The highly active at the beginning strategy group had a high probability of beginning their learning in each topic by applying either the diverse practice-oriented tactice $(p=0.52)$ or the lecture-oriented tactic $(p=0.42)$. 


\section{JOURNAL OF LEARNING ANALYTICS}

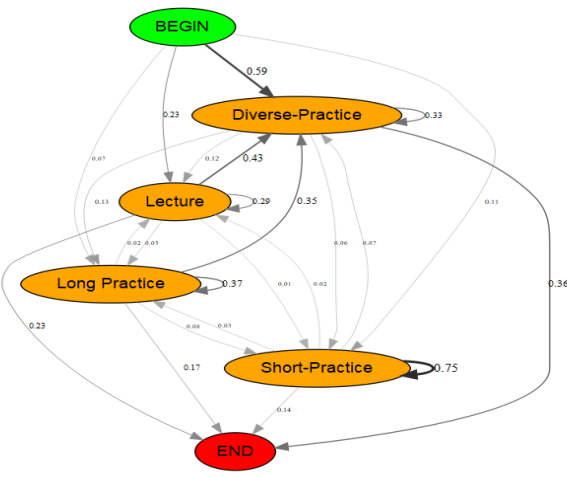

(a) Inactive

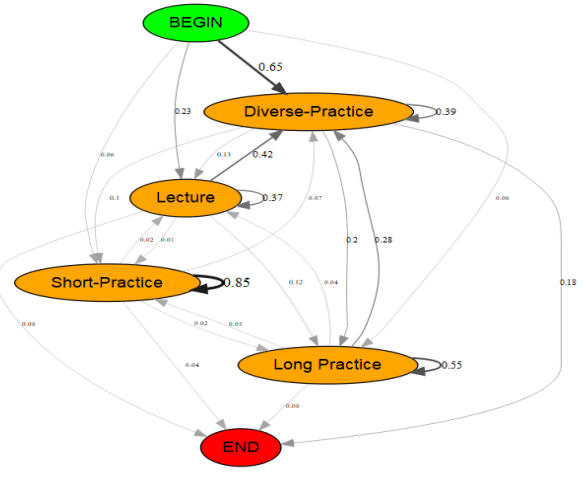

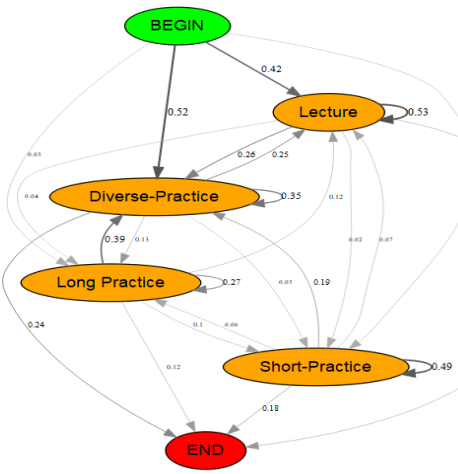

(b) Highly active at the beginning

(c) Highly active

Figure 10. The Process of Tactic Application on a Related Learning Topic in the Introduction to Python Course

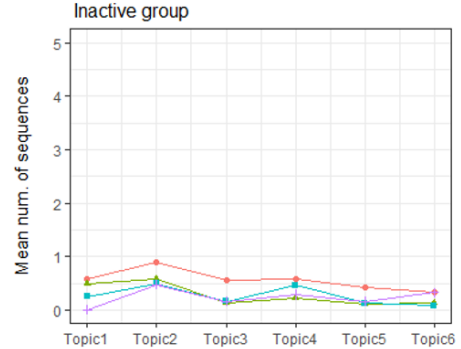

Course Topi

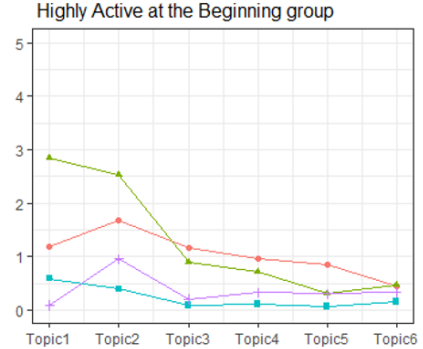

Course Topic

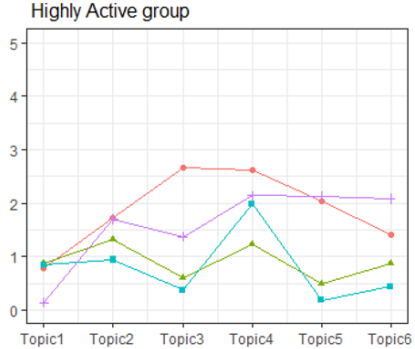

Course Topic
Learning tactics

-- Tactic1: Diverse Oriented

- Tactic2: Lecture-Based Oriented

- Tactic3: Short-Practice Oriented

- Tactic4. Long-Practice Oriented

Figure 11. Learning Strategies Detected in the Introduction to Python Course

They had a strong probability of reusing the lecture-oriented tactic $(p=0.53)$. Similar to the inactive strategy, transitions from long-practice to diverse-practice tactics could also be observed $(p=0.39)$. This strategy group had equal transitions between the lecture- and diverse practice-oriented tactics. The highly active strategy group emphasized the use of the diversepractice tactic. They had a strong probability of beginning their learning in each topic with a long session of the diverse practice-oriented tactic $(p=0.65)$. A transition from the lecture-oriented tactic to the diverse practice-oriented tactic $(p=0.42)$ was observed. The most dominant transition in the highly active strategy group was the repetition of the short practice-oriented tactic $(p=0.85)$. This indicates that students tended to practice by repeatedly doing the exercises designed for each topic covered in the course.

\subsection{RQ2: Associations between Learning Strategies and Academic Performance}

Computer Engineering. Summary statistics for students' course performance per learning strategy group are presented in Table 7. Kruskal-Wallis tests showed a significant association between student learning strategy groups and students' course performance $(p<0.0001)$ for both midterm and final exam scores. To further examine the associations between the detected 
learning strategies and students' academic performance, we did pairwise comparisons of learning strategy groups with respect to the midterm and final exam scores.

Table 7. Summary Statistics (median, first and third quartile) for Course Score for Each Strategy Group

\begin{tabular}{lllll}
\hline Course & Performance & Highly selective & Strategic & Intensive \\
\hline $\begin{array}{l}\text { Computer en- } \\
\text { gineering }\end{array}$ & Midterm (20) & $12(10-15)$ & $15(12-17)$ & $15(12-17)$ \\
& Final exam (40) & $15(10-20)$ & $21(14-30)$ & $22(16-32)$ \\
\hline \multirow{2}{*}{ Biology } & Total score (100) & Highly Selective & Strategic & Intensive \\
\hline \multirow{2}{*}{ Python } & & $63.7(48.0-75.5)$ & $71.3(59.0-78.1)$ & $71.4(62.1-81.2)$ \\
& Total score (100) & Inactive & Highly Active at the Beginning & Highly Active \\
\hline & Passed graded item (22) & $7.0(2.0-15.0)$ & $5.0(2.0-16.0)$ & $82.7(54.2-89.6)$ \\
\end{tabular}

As shown in Table 8, significant differences with respect to both midterm and final exam scores were present between strategy 1 - strategic and strategy 2 - highly selective and between strategy 3 - intensive and strategy 2 - highly selective. However, no statistically significant difference was found between the strategy 1 - strategic and strategy 3 - intensive groups with respect with midterm and final exam scores.

Table 8. Pairwise Comparison of Strategy Groups with Respect to the Scores

\begin{tabular}{|c|c|c|c|c|c|}
\hline Performance & Strategy & Strategy & Z & $\mathrm{p}$ & 1 \\
\hline ComEng: & Strategic — moderate engagement & Highly selective — low engagement & 9.329 & $<0.0001^{*}$ & 0.31 \\
\hline \multirow{2}{*}{$\begin{array}{l}\text { Midterm } \\
\text { score }\end{array}$} & Strategic - moderate engagement & Intensive - high engagement & -0.1577 & 0.875 & 0.01 \\
\hline & $\begin{array}{l}\text { Highly selective - low engage- } \\
\text { ment }\end{array}$ & Intensive - high engagement & -7.0258 & $<0.0001 *$ & 0.28 \\
\hline \multirow{3}{*}{$\begin{array}{l}\text { Final } \\
\text { exam } \\
\text { score }\end{array}$} & Strategic - moderate engagement & Highly selective - low engagement & 9.338 & $<0.0001 *$ & 0.311 \\
\hline & Strategic - moderate engagement & Intensive - high engagement & -1.851 & 0.064 & 0.077 \\
\hline & $\begin{array}{l}\text { Highly selective - low engage- } \\
\text { ment }\end{array}$ & Intensive - high engagement & -8.847 & $<0.0001^{*}$ & 0.366 \\
\hline \multirow{3}{*}{$\begin{array}{l}\text { Biology: } \\
\text { Course } \\
\text { score }\end{array}$} & Intensive - high engagement & Strategic - moderate engagement & 0.841 & 0.34 & 0.051 \\
\hline & Intensive - high engagement & Highly selective - low engagement & 3.568 & $<0.0001 *$ & 0.208 \\
\hline & Strategic - moderate engagement & Highly selective - low engagement & 3.628 & $<0.0001^{*}$ & 0.18 \\
\hline \multirow{3}{*}{$\begin{array}{l}\text { Python: } \\
\text { Course } \\
\text { score }\end{array}$} & Inactive & Highly active at the beginning & 0.108 & 0.914 & 0.006 \\
\hline & Inactive & Highly active & -6.927 & $<0.0001 *$ & 0.415 \\
\hline & Highly active at the beginning & Highly active & -5.879 & $<0.0001^{*}$ & 0.475 \\
\hline
\end{tabular}

Note: * marks statistically significant differences.

Biology. Table 7 presents the median and first and third quartiles of the course marks of the biology course. Average exam marks of the intensive - high engagement and strategic - moderate engagement strategy groups were almost equal (median = 71.4 and 71.3, respectively), but the highly selective - low engagement group had lower average course marks (median = 63.7). Kruskal-Wallis tests revealed a statistically significant difference $(p<0.0001)$ among the learning strategy groups with respect to total course score. The results of the followup pairwise comparisons of the strategy groups are presented in Table 8 . Significant differences in total course score were present between intensive — high engagement and highly selective — low engagement and between strategic — moderate engagement and highly selective — low engagement.

Python. The performance indicator in the introduction to Python course was the final course mark. The median and first and third quartiles of the performance indicators for each learning strategy group are presented in Table 7. The inactive and highly active at the beginning strategy groups showed relatively low average course marks (median $=29.3$ and 20.4, respectively). The highly active group achieved high average course marks (median $=82.7$ ), well above the other two strategy groups. The Kruskal-Wallis test confirmed the statistical difference among the strategy groups with respect to the course grade. The pairwise comparisons of the strategy groups are presented in Table 8. Significant differences were observed between strategy 2 - highly active at the beginning and strategy 3 - highly active and between strategy 1 - inactive and strategy 3 - highly active. 


\section{Discussion}

\subsection{RQ1: Tactics and Strategies Detection}

\subsubsection{The Detected Tactics and the Differences in Learning Contexts}

The results indicate that the course design shaped the selection of learning activities and, consequently, led to the adoption of diverse learning tactics (Winne \& Hadwin, 1998). For instance, in the computer engineering course, a variety of learning activities were available, including video lectures, quizzes, practical exercises, and reading materials (Table 3). Even though the dominant learning actions were those related to the practical exercises $(42 \%)$, other learning activities shared a relatively high frequency of use (more than $10 \%$ for each activity). The adopted analytic method based on process mining led to the detection of distinct clusters of students' learning sequences (i.e., completed learning sessions), characterized by different dominant actions and different composition of actions in learning sequences (Figure 2 and Table 4). As such, these clusters are representative of the patterns in students' learning behaviour and indicative of the learning tactics that students used.

Meanwhile, the design of the introduction to Python course placed primary focus on practice through coding exercises (Table 3). This focus was reflected in the detected learning tactics. In particular, apart from one (lecture-based) tactic, we identified three distinct tactics associated with the practical exercises. For instance, students interacted with the practical exercises either by continuously working on a problem for a long period of time (i.e., the long practice-oriented tactic) or by breaking the practical exercises into smaller sessions (i.e., the short practice-oriented tactic) or combining the practical exercises with other learning activities in a long session (i.e., the diverse practice exam-oriented tactic).

In contrast to the two problem solving-based courses, the online learning activities of the biology course were designed to support self-revision through reading materials, discussion, and self-preparation of the lab activities. The actions in the biology course contained more than $70 \%$ of navigation to the course homepage, which consisted of the general information, structure, and objectives of the course, and the reading materials (28\% accessing the homepage and $44 \%$ accessing the reading materials). Therefore, the three detected learning tactics contained reading activities with different characteristics. One tactic was characterized by actions related to the reading materials and homepage. Another tactic was about reading and pre-lab-related activities. The last tactic focused on activities related to reading and discussion. Common to all tactics were short learning sessions.

Even though the tactics detected across the three learning contexts were different, the proposed analytic method could be applied to detect learning patterns indicative of learning tactics in these contexts. Moreover, by replicating the method, we observed that the tactics detected in different learning conditions reflected the design of the course. In particular, we recognized two features of the tactics that defined them. The first feature is the type of the learning actions within a tactic. These learning actions reflected how a course was designed. The type of learning action defined the main focus of students in each learning tactic (e.g., focusing on the reading material in the reading-oriented tactic). The second feature is the length of sessions in which the tactics were applied. This reflects the technique students used to direct the learning. For instance, in the Python course, students either interacted with the practical exercises by dividing the tasks into short practical exercises or interacted with the tasks for a long-practice session. Hence, the pattern of the detected learning tactics reflected the design of the course. This notion is well confirmed by SRL theory, which emphasizes the role of instructional and course design on the selection of learning tactics (Winne \& Hadwin, 1998).

\subsubsection{The Strategies Detected across the Different Learning Contexts}

The detected learning strategies are aligned with the well-defined approaches to learning as described by Entwistle (1991), Marton and Säljö (1976), and Biggs (1987). Approaches to learning are situation, content, and intuition dependent. In other words, the goal and motivation of individual students (intuition), the way in which learning was carried out (the situation), and the content that students needed to learn play highly important roles in the selection of the approach to learning (Entwistle, 2007). This notion is well aligned with SRL theory, which emphasizes the influence of task and cognitive conditions on the selection of learning strategies (Winne \& Hadwin, 1998). Entwistle (1991) and Biggs (1987) defined three approaches to learning, extended from the initial concept of approaches to learning proposed by Marton and Säljö (1976), namely surface, deep, and strategic approaches to learning.

- Surface approach to learning: This approach to learning is characterized by a superficial method of learning where the focus is mainly on assessment, with a lack of understanding of content (Entwistle, 1991). Students use shortcuts to reduce the time they need to devote to the learning activities.

Students who used the highly selective - low engagement strategy from the computer engineering course, as well as the inactive strategy group from the Python course, are good representatives of this approach to learning. The low level of engagement in each week (i.e., in relation to each topic, for the Python course) demonstrates a lack of intention and effort toward accomplishing a higher order of thinking. The assessment tactic is the only consistently used tactic of these two strategy groups. 
The surface learner is also characterized by focusing on a portion of learning facts and often jumping to conclusions, as demonstrated by the use of a single learning tactic (reading oriented) and directly jumping to the assessment tasks in the highly selective - low engagement group during the first half of the semester of the computer engineering course (Chonkar et al., 2018; Jovanović et al., 2017). Students interacted with the basic learning concept activities slightly. Moreover, students barely realized the value of the ungraded formative assessment (i.e., quizzes). Even though a consistent use of practical exercises (i.e., the adoption of the practice-oriented technique) is highlighted by many researchers (e.g., Bjork, Dunlosky, and Kornell (2013); Dunlosky, Rawson, Marsh, Nathan, and Willingham (2013)) as effective, when superficially applied, without proper understanding of the basic concepts, it cannot reach its potential effectiveness. Therefore, students in the highly selective - low engagement strategy group did not fully utilize the learning opportunities that were offered to them.

In contrast to the two courses focused on problem-solving activities, the biology course offered few online practical exercises to students. Our process-mining approach detected one type of learning strategy in this course that represented surface engagement, namely the highly selective - low engagement strategy group. Students in this strategy group were active at the beginning of the course, but their level of engagement dropped significantly after the fourth week. The exams proved to be the only motivating element, as only the exam periods (weeks 7 and 13) were associated with higher levels of engagement. This behavioural pattern also reflected students' focus on assessment.

- Deep approach to learning: This approach to learning, characterized by active engagement in various learning activities, is considered desirable (Marton \& Säljö, 1976), since a number of research studies have reported a positive impact of deep learning approaches on academic performance (Chonkar et al., 2018). In our study, students who used the intensive - high engagement strategy from the computer engineering course, the intensive strategy from the biology course, and the highly active strategy from the Python course reflect the use of the deep approach to learning. The high level of engagement of these strategy groups indicates an active concentration and high amount of effort by students. Moreover, students used a diverse set of learning tactics and completed various learning activities, including multiple interactions with practical exercises. The performance of students who employed these strategies tended to be the highest among the three groups of strategies identified in each of the three contexts. This finding is consistent with previous research results suggesting that the deep approach to learning is associated with a high level of performance (Marton \& Säljö, 1976; Zeegers, 2001).

- Strategic approach to learning: Strategic learning is also referred to as the achieving learning approach (Biggs, 1987). It is the study approach of choice for those students whose primary intention is to achieve high performance (Diseth \& Martinsen, 2003). Similar to surface learning, the focus is on assessment, but a considerable amount of effort is also put into understanding the topic under study. Therefore, strategic learners combine surface and deep approaches to learning (Chonkar et al., 2018), and they often do well with time and study management. Among the detected learning strategy groups, strategic - moderate engagement from the computer engineering course and the biology course are clear representatives of the strategic approach to learning. Students in these groups put in a moderate amount of effort as compared to the other two groups i.e., intensive - high engagement and highly selective — low engagement, yet they achieved a high performance level. The strategic students from the computer engineering course were consistently concentrated on the assessment activities, as evident in the extensive use of the exercise-oriented tactic. In the biology course, the preparation of the pre-lab activities was observed for the strategic students mainly during the weeks when these preparations were a requirement. This demonstrates strategic planning of the time to devote to completing the course requirements. During weeks 7 and 13, when the exams were scheduled, a higher level of engagement than in other weeks was observed for these students. This is a further confirmation of the strategic approach of this strategy group.

Unlike the FC and BL modalities, in the Python course delivered through a MOOC, we detected the highly active at the beginning strategy group. Students strategically relied on a select subset of learning tactics at the beginning of the course (first two course topics); that is, they heavily employed the lecture based- and diverse practice-oriented tactics. The tactics used by this particular strategy group suggest that students might not have been familiar with or may have had a minimal background in programming. Contrary to the nature of problem solving-based learning, students employed the lecture-based tactic in several learning sessions. Being based on rewatching the video lectures, this tactic can be considered a passive and less effective learning technique (Dunlosky et al., 2013). Due to the ineffective learning tactic used, it is reasonable to believe that students in this strategy group faced some difficulties understanding the course content. Despite a few attempts to deal with the practical exercises, the level of engagement consistently dropped from the third topic onward. The deep approach to learning applied when interacting with the first two course topics was then replaced by the surface approach to learning.

A possible explanation of this finding is that students with backgrounds in different subject domains and lack of prior knowlege of the topics under study may opt for a particular strategy they are familiar with (as reflected by the choices of 
their tactics). However, the selected strategy may not be suitable for the discipline and/or topic in the given course. This is particularly emphasized in the success of learners when they take not-for-credit courses (MOOC) where the stakes of investment are lower and the backgrounds of learners much more diverse than in for-credit courses.

Overall, we observed that in the learning contexts where online learning was accompanied by face-to-face activities (i.e., BL and FC), similar learning strategies were observed. That is, students consistently exhibited either the deep, the surface, or the strategic approach to learning throughout the course. However, in the MOOC, we detected two learning strategies representing the deep and surface approaches to learning and one learning strategy exhibiting a transition from deep to surface approach, i.e., the highly active at the beginning strategy group.

\subsection{RQ2: Association between Learning Strategies and Academic Performance}

This study found that students who used a variety of learning tactics tended to have higher performance than those who relied on a single tactic. Some of the employed tactics were general, passive, and less effective, such as rereading (Dunlosky, 2013) or re-watching lecture videos (Dunlosky et al., 2013), but some were course specific and more effective, such as practical testing as demonstrated by the frequent use of the exercise-oriented tactic and the MCQ-oriented tactic. Similarly, Fincham et al. (2018); Gašević, Jovanović, Pardo, and Dawson (2017); and Nandagopal and Ericsson (2012) found that students who engaged in various learning tactics had a tendency to perform better. High-achieving learners know when, where, and how to apply learning tactics and strategies (Pressley, Borkowski, \& Schneider, 1987).

Referring again to students' approaches to learning, the deep and strategic approaches to learning are the desirable ones, associated with higher performance (Chonkar et al., 2018; Mattick, Dennis, \& Bligh, 2004), whereas the surface approach to learning is less desirable and associated with low performance. Consistent with the literature, the current study found that students who used the highly selective - low engagement strategy from the computer engineering course, the inactive strategy from the Python course, and the highly selective - low engagement strategy from the biology course, thus reflecting the surface approach to learning, performed poorer than those who used one of the other two learning strategies (Byrne, Flood, \& Willis, 2010). We also observed that students in the highly active at the beginning strategy group from the Python course showed a relatively low level of academic performance. The academic performance was mostly obtained from the first two course topics, where they were deeply engaged with the learning content. Later, students exhibited surface learning when interacting with the rest of the course topics (i.e., from topics 3 to 6 ).

We observed no significant association in terms of pairwise comparison between the strategic - moderate engagement strategy and the intensive - high engagement strategy in the computer engineering course and in the biology course. This corresponds to the use of the strategic and deep approaches to learning, respectively. Considering that these two approaches to learning are known to be associated with high academic performance (Byrne et al., 2010; Zeegers, 2001), it was not surprising that we found no difference in academic performance between these two groups. The amount of effort exerted by the strategic - moderate engagement group declined after the midterm test. Prior research has denoted the role of engagement as one of the success factors in learning (Dabbagh, 2007). Hence, our finding that the intensive - high engagement strategy group performed better on the final exam than the strategic - moderate engagement group corroborates the findings of several empirical studies that demonstrated that a higher level of engagement showed a significant association with course achievement (Lee, 2014; Fincham et al., 2018). Effective learners are those who not only chose the effective learning strategies but also realized that learning requires effort (Pressley et al., 1987; Winne, 2013).

To sum up, our exploration across three different learning contexts revealed that higher levels of engagement and application of diverse learning tactics were associated with higher academic performance. Students who employed the learning strategies that reflected the deep or strategic approaches to learning obtained higher learning performance than those who applied the surface approach to learning. These findings are well aligned with several empirical studies on the approaches to learning and association with academic performance (Dabbagh, 2007; Byrne et al., 2010; Zeegers, 2001; Chonkar et al., 2018; Mattick et al., 2004).

\section{Conclusions}

\subsection{Summary of Contributions}

This study aimed to explore the dynamics of students' learning tactics across different course designs that were delivered by using different modalities. The main contributions of the study include, first, an analytic method for discovering latent patterns in students' learning behaviour, which are reflective of students' learning tactics and strategies. As latent constructs, learning tactics and strategies cannot be directly observed in the collected trace data but need to be extracted using appropriate statistical or machine-learning algorithms. We have detected tactics at the level of learning sessions, extracted learning strategies from the patterns of use of the identified tactics, and interpreted the meaning of the detected learning tactics and strategies by considering their temporal and sequential attributes from the perspective of the relevant learning theories (SRL and approaches to learning). 
Second, we validated the proposed method across several learning contexts in terms of the dependency of the detected tactics and strategies on the mode of course delivery and the course design. The proposed method provided detailed insights into how student complete online learning activities across three different learning contexts, that is, BL, FC, and MOOC. The detected tactics and to a lesser extent strategies are context dependent. That is, the specific learning tactics and strategies have to be interpreted in the particular learning context the trace data originated from (Gašević et al., 2016; Gašević, Dawson, \& Siemens, 2015; Winne, 2013). The interpretation should consider both the chronological ordering and the temporal dimension because learning tactics and strategies are "dynamic constructs" and change over time. We found that the detected tactics were likely to depend on the design of the learning tasks and activities of the courses. That is, the detected tactics represent the techniques used by students to accomplish the learning tasks. For instance, the design of the Python course accentuated practical exercises, and different manners of students' interactions with the practical exercises were reflected in the detected learning tactics. The biology course encouraged students to review the reading materials; accordingly, we detected different reading behaviours. The design of the computer engineering course included a variety of learning tasks; our method detected distinctive tactics, with each tactic representing one dominant learning task. Meanwhile, the detected strategies were less sensitive to the course design; that is, we detected a rather consistent pattern of tactic use across the courses. Across different learning modalities, we detected the behaviours of applying surface, deep, and strategic approaches to learning.

\subsection{Limitations}

This research provides some novel insight into the field. It shows promising results for tactic and strategy detection from trace data and their associations with academic performance across three different learning contexts. However, the study also has certain limitations. First, the study was based on data about online activities, which means students' engagement in face-to-face sessions or individual offline learning was not analyzed. Even though online activities play an important role in supporting the development of conceptual understanding and aid in-class activities, in-class and offline learning activities contribute to deepening of students' understanding and consequently affect their course performance, especially in the case of the BL and FC contexts. Furthermore, students' demographics and previous knowledge were not considered due to the terms and conditions imposed by the institutional ethics approvals.

The methods used to detect learning tactics and strategies (EM and hierarchical clustering) belong to the group of unsupervised machine-learning methods, which, by their nature, introduce a certain level of subjectivity. The validity of the analytics method is explored in terms of how the results are supported by the learning contexts and educational theory as suggested by several scholars (Gašević et al., 2015; Joksimović, Kovanović, \& Dawson, 2019; Matcha, Ahmad Uzir, et al., 2019). Therefore, the explanation of the identified tactics and strategies is subjected to the theory of how tactics and strategies are composed (Maldonado-Mahauad et al., 2018; Pardo et al., 2018). However, the use of self-reports (Zhou \& Winne, 2012; Gašević, Jovanović, et al., 2017) or multimodal techniques to capture students' motivation and goals could help in further validating the study results.

In spite of the stated limitations, our findings are consistent with the literature. The detected learning tactics and strategies are meaningful in the learning context and in accordance with learning theories (Biggs, 1987; Entwistle, 1991), which demonstrates that the findings have merit and can inform future research.

\subsection{Implications}

To answer the call for generalization of learning analytics methods as highlighted by Baker (2019), we have demonstrated the use of an analytics method in detection of learning tactics and strategies across three different learning contexts. This study provided robust evidence for the cross-context applicability of the proposed method. The implications derived from this study are as follows:

Implications for research: Future direction of the research in learning strategies detection should incorporate offline data to better understand the learning strategies used by students, especially in the FC and BL contexts. For instance, multimodal learning analytics could be used to triangulate the online and offline data. How offline learning tactics and strategies complement and/or support online learning tactics and strategies is under-explored.

Furthermore, replication of the analytics-based method across different learning contexts has provided important insight into how students' learning behaviour — that is, their learning tactics and strategies — tend to be shaped by the course design and the delivery modalities. Hence, through replication, we were able to come up with new insight into the learning process. This result further highlights the call for replication studies in learning analytics research, as suggested by Baker (2019).

Implications for teachers: Research highlights the importance of learning strategies (Winne \& Hadwin, 1998; Lust et al., 2013a). Nonetheless, students rarely receive advice on how to choose learning strategies and apply them effectively (Matcha, Ahmad Uzir, et al., 2019). The proposed method could be used to bridge this gap. Our method for detecting learning tactics and strategies could help teachers to gain insight into students' learning behaviours. Hence, necessary support could be provided to those who might need it. For instance, advice could be provided to students on how to apply effective learning tactics and 
strategies by using customized feedback messages, that is, personalized feedback. (McCabe, 2011) conducted an experiment on students' awareness of effective learning strategies. She found that the experimental group that received instruction on effective learning strategies outperformed the group of students that did not receive any strategy-related advice. Therefore, informing students about the value of effective learning strategies can lead to an improvement in academic performance. Similarly, informing students about the benefits of effective learning tactics and strategies can increase their intention to apply them (Clarebout, Elen, Collazo, Lust, \& Jiang, 2013). Previous studies showed that by customizing the feedback to suit the given learning situation, learners could be provided with help for improving their academic performance (Matcha, Gašević, Ahmad Uzir, Jovanović, \& Pardo, 2019; Lim et al., 2019). The provision of personalized feedback, however, requires precise information of a student's learning situation. Hence, employing the proposed method to detect the tactics and strategies used by students could help instructors identify students in need and offer them suggestions on effective tactics and strategies for the given learning situations. This reinforces the role of instructors in tailoring the feedback that corresponds to the requirements of students. It also facilitates the work of instructors in observing the learning progress of their students.

Furthermore, the detected learning tactics and strategies could be used to support the redesign of the course. For instance, the learning strategies showed that in certain weeks and/or course topics, students exhibited high engagement and application of diverse learning tactics. These behaviours inform the importance and/or the difficulty experienced by students in understanding the learning content. Hence, taking students' behaviour when interacting with the course content into account could inform instructors on how to redesign their courses.

\section{Funding}

This research was partially supported by Dirección de Investigación de la Universidad de Cuenca (DIUC), Cuenca-Ecuador, under the project "Analítica del aprendizaje para el estudio de estrategias de aprendizaje autorregulado en un contexto de aprendizaje híbrido" (DIUC_XVIII_2019_54).

\section{Declaration of Conflicting Interest}

The authors declared no potential conflicts of interest with respect to the research, authorship, and/or publication of this article.

\section{References}

Baker, R. S. (2019). Challenges for the future of educational data mining: The Baker Learning Analytics Prizes. Journal of Educational Data Mining, 11(1), 1-17. https://dx.doi.org/10.5281/zenodo.3554746

Bernard, R. M., Borokhovski, E., Schmid, R. F., Tamim, R. M., \& Abrami, P. C. (2014, 4). A meta-analysis of blended learning and technology use in higher education: from the general to the applied. Journal of Computing in Higher Education, 26(1), 87-122. https://dx.doi.org/10.1007/s12528-013-9077-3

Biggs. (1987). Student approaches to learning and studying. Retrieved from https://eric.ed.gov/?id=ED308201

Bjork, R. A., Dunlosky, J., \& Kornell, N. (2013). Self-regulated learning: Beliefs, techniques, and illusions. Annual Review of Psychology, 64(1), 120928131529005. https://dx.doi.org/10.1146/annurev-psych-113011-143823

Broadbent, J. (2017). Comparing online and blended learner's self-regulated learning strategies and academic performance. The Internet and Higher Education, 33, 24-32. https://dx.doi.org/10.1016/j.iheduc.2017.01.004

Broadbent, J., \& Poon, W. L. (2015). Self-regulated learning strategies \& academic achievement in online higher education learning environments: A systematic review. Internet and Higher Education, 27, 1-13. https://dx.doi.org/10.1016/j.iheduc.2015.04.007

Byrne, M., Flood, B., \& Willis, P. (2010). The relationship between learning approaches and learning outcomes: A study of Irish accounting students. Accounting Education, 11, 27-42. https://dx.doi.org/10.1080/09639280210153254

Chonkar, S. P., Ha, T. C., Chu, S. S. H., Ng, A. X., Lim, M. L. S., Ee, T. X., ... Tan, K. H. (2018). The predominant learning approaches of medical students. BMC Medical Education, 18(1), 1-8. https://dx.doi.org/10.1186/s12909-018-1122-5

Clarebout, G., Elen, J., Collazo, N. A. J., Lust, G., \& Jiang, L. (2013, 1). Metacognition and the use of tools. In R. Azevedo \& V. Aleven (Eds.), International handbook of metacognition and learning technologies (pp. 187-195). New York: Springer.

Dabbagh, N. (2007). The online learner: Characteristics and pedagogical implications. Contemporary Issues in Technology and Teacher Education, 7(3), 217-226. Retrieved from https://citejournal.org/volume-7/issue-3-07/general/the-online-learner-characteristics-and-pedagogical-implications/

Derry, S. J. (1989). Putting learning strategies to work. Educational Leadership, 47(5), 4-10.

DiFrancesca, D., Nietfeld, J. L., \& Cao, L. (2016). A comparison of high and low achieving students on self-regulated learning variables. Learning and Individual Differences, 45, 228-236. https://dx.doi.org/10.1016/j.lindif.2015.11.010 
Diseth, A., \& Martinsen, (2003). Approaches to learning, cognitive style, and motives as predictors of academic achievement. Educational Psychology, 23(2), 195-207. https://dx.doi.org/10.1080/01443410303225

Dunlosky, J. (2013). Strengthening the student toolbox: Study strategies to boost learning. American Educator, 37(3), 12-21. Retrieved from http://www.aft.org/sites/default/files/periodicals/dunlosky.pdf

Dunlosky, J., Rawson, K. A., Marsh, E. J., Nathan, M. J., \& Willingham, D. T. (2013, 1). Improving students' learning with effective learning techniques: Promising directions from cognitive and educational psychology. Psychological Science in the Public Interest, 14(1), 4-58. https://dx.doi.org/10.1177/1529100612453266

Entwistle, N. J. (1991). Approaches to learning and perceptions of the learning environment: Introduction to the special issue. Higher Eduation, 22(3), 201-204. https://dx.doi.org/10.1007/BF00132287

Entwistle, N. J. (2007, 10). Research into student learning and university teaching. The British Psychological Society, 1-18. Retrieved from https://www.ingentaconnect.com/content/bpsoc/slaut/2007/00000001/00000001/art00001

Eriksson, T., Adawi, T., \& Stöhr, C. (2017, 4). "Time is the bottleneck": A qualitative study exploring why learners drop out of MOOCs. Journal of Computing in Higher Education, 29(1), 133-146. https://dx.doi.org/10.1007/s12528-016-9127-8

Ferreira, D. R., \& Gillblad, D. (2009). Discovering process models from unlabelled event logs. Business Process Management, 5701, 143-158. https://dx.doi.org/10.1007/978-3-642-03848-8 1

Fincham, O. E., Gašević, D. V., Jovanović, J. M., \& Pardo, A. (2018). From study tactics to learning strategies: An analytical method for extracting interpretable representations. IEEE Transactions on Learning Technologies, 1382(c), 1-14. https://dx.doi.org/10.1109/TLT.2018.2823317

Freeman, S., Eddy, S. L., McDonough, M., Smith, M. K., Okoroafor, N., Jordt, H., \& Wenderoth, M. P. (2014). Active learning increases student performance in science, engineering, and mathematics. Proceedings of the National Academy of Sciences, 111(23), 8410-8415. https://dx.doi.org/10.1073/pnas.1319030111

Gabadinho, A., Ritschard, G., Studer, M., \& Muller, N. S. (2008). Mining sequence data in R with the TraMineR package: A user's guide. Department of Econometrics and Laboratory of Demography, University of Geneva, Switzerland, 1, 1-124. Retrieved from http://mephisto.unige.ch/traminer

Gašević, D., Dawson, S., Rogers, T., \& Gašević, D. (2016). Learning analytics should not promote one size fits all: The effects of instructional conditions in predicting academic success. Internet and Higher Education, 28, 68-84. https://dx.doi.org/10.1016/j.iheduc.2015.10.002

Gašević, D., Dawson, S., \& Siemens, G. (2015). Let's not forget: Learning analytics are about learning. TechTrends, 59(1). https://dx.doi.org/10.1007/s11528-014-0822-x

Gašević, D., Jovanović, J., Pardo, A., \& Dawson, S. (2017). Detecting learning strategies with analytics: Links with self-reported measures and academic performance. Journal of Learning Analytics, 4(2), 113-128. https://dx.doi.org/10.18608/jla.2017.42.10

Gašević, D., Kovanović, V., \& Joksimović, S. (2017). Piecing the learning analytics puzzle: A consolidated model of a field of research and practice. Learning: Research and Practice, 3(1), 63-78. https://dx.doi.org/10.1080/23735082.2017.1286142

Gašević, D., Mirriahi, N., Dawson, S., \& Joksimović, S. (2017). Effects of instructional conditions and experience on the adoption of a learning tool. Computers in Human Behavior, 67, 207-220. https://dx.doi.org/10.1016/j.chb.2016.10.026

Gatta, R., Lenkowicz, J., Vallati, M., \& Stefanini, A. (2017). pMineR: Processes mining in medicine. Retrieved from https://cran.r-project.org/package=pMineR

Hadwin, A. F., Nesbit, J. C., Jamieson-Noel, D., Code, J., \& Winne, P. H. (2007). Examining trace data to explore self-regulated learning. Metacognition and Learning, 2(2-3), 107-124. https://dx.doi.org/10.1007/s11409-007-9016-7

Joksimović, S., Kovanović, V., \& Dawson, S. $(2019,1)$. The journey of learning analytics. HERDSA Review of Higher Education, 6, 37-63. Retrieved from www.herdsa.org.au/herdsa-review-higher-education-vol-6/37-63

Jovanović, J., Gašević, D., Dawson, S., Pardo, A., \& Mirriahi, N. (2017). Learning analytics to unveil learning strategies in a flipped classroom. The Internet and Higher Education, 33, 74-85. https://dx.doi.org/10.1016/j.iheduc.2017.02.001

Kizilcec, R. F., Pérez-Sanagustín, M., \& Maldonado, J. J. (2017). Self-regulated learning strategies predict learner behavior and goal attainment in massive open online courses. Computers \& Education, 104, 18-33. https://dx.doi.org/http://dx.doi.org/10.1016/j.compedu.2016.10.001

Kovanović, V., Gašević, D., Joksimović, S., Hatala, M., \& Olusola, A. (2015). Analytics of communities of inquiry: Effects of learning technology use on cognitive presence in asynchronous online discussions. Internet and Higher Education, 27, 74-89. https://dx.doi.org/10.1016/j.iheduc.2015.06.002

Lai, C. L., \& Hwang, G. J. (2016, 9). A self-regulated flipped classroom approach to improving students' learning performance in a mathematics course. Computers and Education, 100, 126-140. https://dx.doi.org/10.1016/j.compedu.2016.05.006

Lee, J.-s. (2014). The relationship between student engagement and academic performance: Is it a myth or reality? The Journal of Educational Research, 107(3), 177-185. https://dx.doi.org/10.1080/00220671.2013.807491 
Lim, L. A., Gentili, S., Pardo, A., Kovanović, V., Whitelock-Wainwright, A., Gašević, D., \& Dawson, S. (2019). What changes, and for whom? A study of the impact of learning analytics-based process feedback in a large course. Learning and Instruction. https://dx.doi.org/10.1016/j.learninstruc.2019.04.003

Lust, G., Elen, J., \& Clarebout, G. (2013a). Regulation of tool-use within a blended course: Student differences and performance effects. Computers and Education, 60(1), 385-395. https://dx.doi.org/10.1016/j.compedu.2012.09.001

Lust, G., Elen, J., \& Clarebout, G. (2013b). Students' tool-use within a web enhanced course: Explanatory mechanisms of students' tool-use pattern. Computers in Human Behavior, 29, 2013-2021. https://dx.doi.org/10.1016/j.chb.2013.03.014

Maldonado-Mahauad, J., Pérez-Sanagustín, M., Kizilcec, R. F., Morales, N., \& Munoz-Gama, J. (2018). Mining theory-based patterns from Big Data: Identifying self-regulated learning strategies in massive open online courses. Computers in Human Behavior, 80, 179-196. https://dx.doi.org/10.1016/j.chb.2017.11.011

Malmberg, J., Järvelä, S., \& Kirschner, P. A. (2014). Elementary school students' strategic learning: Does task-type matter? Metacognition and Learning, 9(2), 113-136. https://dx.doi.org/10.1007/s11409-013-9108-5

Malmberg, J., Järvenoja, H., \& Järvelä, S. (2010). Tracing elementary school students' study tactic use in gStudy by examining a strategic and self-regulated learning. Computers in Human Behavior, 26(5), 1034-1042. https://dx.doi.org/10.1016/j.chb.2010.03.004

Marton, F., \& Säljö, R. (1976). On qualitative differences in learning: I-Outcome and process. British Journal of Educational Psychology, 46(1), 4-11. https://dx.doi.org/10.1111/j.2044-8279.1976.tb02980.x

Matcha, W., Ahmad Uzir, N., Gašević, D., \& Pardo, A. (2019). A systematic review of empirical studies on learning analytics dashboards: A self-regulated learning perspective. IEEE Transactions on Learning Technologies, 1382(c), 1. https://dx.doi.org/10.1109/TLT.2019.2916802

Matcha, W., Gašević, D., Ahmad Uzir, N., Jovanović, J., \& Pardo, A. (2019). Analytics of learning strategies: Associations with academic performance and feedback. In Proceedings of the 9th International Conference on Learning Analytics \& Knowledge (LAK '19), 4-8 March 2019, Tempe, Arizona, USA (pp. 461-470). New York: ACM. https://dx.doi.org/10.1145/3303772.3303787

Matcha, W., Gašević, D., Ahmad Uzir, N., Jovanović, J., Pardo, A., Maldonado-Mahauad, J., \& Pérez-Sanagustín, M. (2019). Detection of learning strategies: A comparison of process, sequence and network analytic approaches. In European Conference on Technology Enhanced Learning (EC-TEL 2019), 16-19 September, Delft, Netherlands (pp. 525-540). Springer. https://dx.doi.org/10.1007/978-3-030-29736-739

Mattick, K., Dennis, I., \& Bligh, J. (2004). Approaches to learning and studying in medical students: Validation of a revised inventory and its relation to student characteristics and performance. Medical Education, 38(5), 535-543. https://dx.doi.org/10.1111/j.1365-2929.2004.01836.x

McCabe, J. (2011, 4). Metacognitive awareness of learning strategies in undergraduates. Memory \& Cognition, 39(3), $462-476$. https://dx.doi.org/10.3758/s13421-010-0035-2

Molenaar, I. (2014). Advances in temporal analysis in learning and instruction. Frontline Learning Research, 6, 15-24. https://dx.doi.org/10.14786/flr.v2i4.118

Nandagopal, K., \& Ericsson, K. A. (2012). An expert performance approach to the study of individual differences in self-regulated learning activities in upper-level college students. Learning and Individual Differences, 22(5), 597-609. https://dx.doi.org/10.1016/j.lindif.2011.11.018

Nugent, G., Guru, A., \& Namuth-Covert, D. (2018). Students' approaches to e-learning: Analyzing credit/noncredit and high/low performers. Interdisciplinary Journal of e-Skills and Lifelong Learning, 14, 143-158. https://dx.doi.org/10.28945/4133

O'Flaherty, J., \& Phillips, C. (2015). The use of flipped classrooms in higher education: A scoping review. Internet and Higher Education, 25, 85-95. https://dx.doi.org/10.1016/j.iheduc.2015.02.002

Olney, T., Rienties, B., \& Toetenel, L. (2018). Gathering, visualising and interpreting learning design analytics to inform classroom practice and curriculum design: A student-centred approach from the Open University. In From Data and Analytics to the Classroom: Translating Learning Analytics for Teachers. London: Routledge. Retrieved from https://www.taylorfrancis.com/books/e/9781351113038/chapters/10.4324/9781351113038-6

Pardo, A. (2018). A feedback model for data-rich learning experiences. Assessment \& Evaluation in Higher Education, 43(3), 428-438. https://dx.doi.org/10.1080/02602938.2017.1356905

Pardo, A., Gašević, D., Jovanović, J. M., Dawson, S., \& Mirriahi, N. (2018). Exploring student interactions with preparation activities in a flipped classroom experience. IEEE Transactions on Learning Technologies. https://dx.doi.org/10.1109/TLT.2018.2858790

Pardo, A., \& Mirriahi, N. (2017). Design, deployment and evaluation of a flipped learning first year engineering course. In C. Reidsema, L. Kavanagh, R. Hadgraft, \& N. Smith (Eds.), The Flipped Classroom: Practice and Practices in Higher Education (pp. 177-191). Singapore: Springer. https://dx.doi.org/10.1007/978-981-10-3413-81 1 
Pérez-Sanagustín, M., Hilliger, I., Alario-Hoyos, C., Kloos, C. D., \& Rayyan, S. (2017, 4). H-MOOC framework: Reusing MOOCs for hybrid education. Journal of Computing in Higher Education, 29(1), 47-64. https://dx.doi.org/10.1007/s12528-017-9133-5

Pressley, M., Borkowski, J. G., \& Schneider, W. (1987). Cognitive strategies: Good strategy users coordinate metacognition and knowledge. Annals of Child Development, 4(2), 89-129.

Proctor, B. E., Prevatt, F. F., Adams, K. S., Reaser, A., \& Petscher, Y. (2006). Study skills profiles of normalachieving and academically-struggling college students. Journal of College Student Development, 47(1), 37-51. https://dx.doi.org/10.1353/csd.2006.0011

Rachal, C. K., Daigle, S., \& Rachal, W. S. (2007). Learning problems reported by college students: Are they using learning strategies? Journal of Instructional Psychology, 34(4), 191-199. Retrieved from https://eric.ed.gov/?id=EJ790467

Rahman, A. A., Aris, B., Rosli, M. S., Mohamed, H., Abdullah, Z., \& Zaid, N. M. (2015). Significance of preparedness in flipped classroom. Advanced Science Letters, 21(10), 3388-3390. https://dx.doi.org/10.1166/asl.2015.6514

Rodríguez, M. F., Correa, J. H., Pérez-Sanagustín, M., Pertuze, J. A., \& Alario-Hoyos, C. (2017). A MOOC-based flipped class: Lessons learned from the orchestration perspective. In Lecture Notes in Computer Science (including subseries Lecture Notes in Artificial Intelligence and Lecture Notes in Bioinformatics) (Vol. 10254 LNCS, pp. 102-112). Springer Verlag. https://dx.doi.org/10.1007/978-3-319-59044-8,2

Tessmer, M., \& Richey, R. C. (1997). The role of context in learning and instructional design. Educational Technology Research and Development, 45(2), 85-115. https://dx.doi.org/10.1007/BF02299526

Winne, P. H. (2006). How software technologies can improve research on learning and bolster school reform. Educational Psychologist, 4l(1), 5-17. https://dx.doi.org/10.1207/s15326985ep4101

Winne, P. H. (2013). Learning strategies, study skills, and self-regulated learning in postsecondary education. Higher Education: Handbook of Theory and Research(28), 337-403. https://dx.doi.org/10.1007/978-90-481-8598-6

Winne, P. H. (2017). Learning analytics for self-regulated learning. In C. Lang, G. Siemens, A. Wise, \& D. Gašević (Eds.), Handbook of learning analytics (pp. 241-249). Society for Learning Analytics Research. https://dx.doi.org/10.18608/hla17.021

Winne, P. H., \& Hadwin, A. F. (1998). Studying as self-regulated learning. In D. J. Hacker, J. Dunlosky, \& A. C. Graesser (Eds.), Metacognition in Educational Theory and Practice (Vol. 93, pp. 277-304). Lawrence Erlbaum Associates.

Winne, P. H., Jamieson-Noel, D., \& Muis, K. (2002). Methodological issues and advances in researching tactics, strategies, and self-regulated learning. In Advances in motivation and achievement: New directions in measures and methods (Vol. 12, pp. 121-155). Emerald Group.

Yip, M. C. W. (2007). Differences in learning and study strategies between high and low achieving university students: A hong kong study. Educational Psychology, 27(4), 597-606. https://dx.doi.org/10.1080/01443410701309126

Zeegers, P. (2001). Approaches to learning in science: A longitudinal study. British Journal of Educational Psychology, 71(1), 115-132. https://dx.doi.org/10.1348/000709901158424

Zhou, M., \& Winne, P. H. (2012). Modeling academic achievement by self-reported versus traced goal orientation. Learning and Instruction, 22(6), 413-419. https://dx.doi.org/10.1016/j.learninstruc.2012.03.004

Zhu, Y., Au, W., \& Yates, G. (2016). University students' self-control and self-regulated learning in a blended course. Internet and Higher Education, 30, 54-62. https://dx.doi.org/10.1016/j.iheduc.2016.04.001

Zimmerman, B. J. (1986). Becoming a self-regulated learner: Which are the key subprocesses? Contemporary Educational Psychology, 11(4), 307-313. https://dx.doi.org/10.1016/0361-476X(86)90027-5 